\title{
POLÍTICAS DE MITIGAÇÃO DE MUDANÇAS CLIMÁTICAS E SEUS EFEITOS SOBRE O BRASIL $^{1}$
}

\author{
Franklin Pedro França ${ }^{2}$ \\ Angelo Costa Gurgel ${ }^{3}$
}

Resumo: O presente trabalho estima os impactos de políticas de mitigação de mudanças climáticas possíveis de serem adotadas pelos EUA, União Europeia (UE) e Brasil em um horizonte futuro de 20 anos. Para tal, utiliza um modelo de equilíbrio geral da economia mundial, construído para projetar emissões de gases de efeito estufa (GEE) e simular políticas de redução nessas emissões. Os resultados sugerem a necessidade de uma maior participação e cooperação global para estabilizar emissões e reduzir os riscos das mudanças climáticas. Nos EUA e na UE, as políticas climáticas geram perdas de bem-estar de $0,7 \%$ e $0,4 \%$, respectivamente, em 2030, para cortes em emissões de $25 \%$ em relação às emissões de GEE observadas em 2005. O Brasil sofreria perdas de até de $0,3 \%$ em bem-estar em 2030, caso não aplique políticas climáticas, mas enfrente tarifas compensatórias de carbono impostas por aqueles países. Essas barreiras comerciais se mostram pouco eficientes em evitar vazamentos em emissões e a perda de competitividade. Quando o Brasil impõe cortes em emissões, os custos de bem-estar podem atingir até $2,4 \%$ em 2030 , o que sugere menores possibilidades de adoção de tecnologias de baixas emissões e de substituição de fontes de energia fósseis por renováveis. A redução nas emissões do desmatamento apresenta baixos custos de mitigação, enquanto cortes setoriais em emissões se mostram bem menos custoefetivos que outras estratégias, como um mercado de carbono nacional. Os setores de produção e uso de energia fóssil e a agropecuária seriam os maiores prejudicados pela política climática doméstica. $\mathrm{O}$ grande potencial de mitigação pela produção e uso de biocombustíveis no Brasil é confirmado pelo presente estudo, apesar de esse potencial não impedir a queda no nível de atividade do setor de transportes.

Palavras-chave: Política climática, tarifas compensatórias de carbono, gases de efeito estufa, custos de mitigação

1 Recebido em: 05/11/12; Aceito em: 18/02/2013.

2 Faculdade de Economia, Administração e Contabilidade de Ribeirão Preto, Universidade de São Paulo - FEA-RP/USP. E-mail: franklinfranca@gmail.com

3 Escola de Economia de São Paulo, Fundação Getúlio Vargas - EESP/FGV. E-mail: angelo.gurgel@fgv.br 


\begin{abstract}
The study estimates the impacts of climate change policies that may be adopted by US, European Union (EU) and Brazil in a time frame of 20 years. We use a general equilibrium model of the world economy, built to project greenhouse gas (GHG) emissions and simulate policies to reduce such emissions. The results suggest the necessity to a broader global participation and cooperation to stabilize emissions and reduce the risks of climate change. The climate policies generate welfare costs of $0,7 \%$ in the US and $0,4 \%$ in the EU in 2030 from emission cuts of $25 \%$ relative to 2005 GHG emissions. Brazil welfare losses amount $0,3 \%$ in 2030 if it does not applies climate policies but faces carbon tax board adjustments from those developed nations. Such trade barriers are not efficient in avoiding emission leakages and the loss of competitiveness. If Brazil imposes emission cuts, the welfare costs may reach $2,4 \%$ in 2030 , what suggests fewer possibilities to adopt low carbon technologies and to substitute fossil fuel energy by renewable ones. The reduction in emissions from deforestation has low mitigation costs, while the sectorial cuts in emissions are much less cost-effective than other strategies, as a national carbon market. The economic sectors related to the production and high consumption of fossil fuels as also the agricultural sectors faces higher losses by the domestic climate policy. The large mitigation potential from biofuels in Brazil is confirmed by the study, although such potential does not avoid the decrease in the activity level of the transportation sector.
\end{abstract}

Keywords: Climate policy, carbon tax board adjustment, greenhouse gases, mitigation costs

\title{
1. Introdução
}

Durante as últimas décadas do século passado e no início do século XXI, vêm sendo intensificados os debates a respeito das emissões de gases do efeito estufa pelo homem e seus impactos sobre alterações no clima do planeta. O fenômeno conhecido como efeito estufa consiste na acumulação de gases na atmosfera do nosso planeta, associados à manutenção do calor na terra. Os processos naturais associados a esses gases permitiram que se desenvolvessem todas as formas de vida conhecidas. As mudanças climáticas são um fato histórico, tendo ocorrido em diversos períodos da história do nosso planeta (vide a era glacial, por exemplo). 
Contudo, a acumulação excessiva desses gases "aprisiona" a luz solar em demasia e bloqueia a saída de radiação, provocando um aumento da temperatura global com consequências adversas nas diferentes regiões do mundo. Os cientistas que afirmam ser a atividade humana responsável por uma parcela importante do acúmulo de gases causadores do efeito estufa na atmosfera encontram na evolução da temperatura da superfície do globo terrestre em $0,5^{\circ} \mathrm{C}$ ao longo dos últimos 100 anos, período que coincide com o início da revolução industrial, uma confirmação na relação de causa e efeito entre emissões e aumento da temperatura.

Com base nas evidências de que as atividades humanas sejam responsáveis por boa parte do aquecimento global, e considerando os possíveis resultados negativos e até mesmo catastróficos para a economia de muitos países que este aumento acarretaria, debates nacionais, regionais e multilaterais estão se intensificando em direção a um futuro com maior utilização de energias limpas.

O evento mais importante a respeito do comprometimento do mundo na redução das emissões de gases causadores do efeito estufa foi a terceira conferência das partes (COP), realizada em Kyoto, no Japão, em que foi adotado o protocolo de mesmo nome, que entrou em vigor em 2005. Este protocolo estabeleceu que os países industrializados reduzissem as emissões de gases de efeito estufa (GEE) com relação aos níveis de 1990 em 5,2\%, em média, entre os anos de 2008 e 2012.

Em 2007, o G8 propôs uma meta de redução de 50\% nas emissões mundiais dos países desenvolvidos e em desenvolvimento até 2050. Esta meta prevê que os países em desenvolvimento devem se comprometer a reduzir emissões entre $10 \%$ e $30 \%$ até 2020 , e os desenvolvidos, entre $25 \%$ e $40 \%$ no mesmo período (Intergovernmental Panel On Climate Change- IPCC, 2007). Em 2050, todos os países deveriam atingir a meta de $50 \%$ nas reduções de poluentes atmosféricos (G-8 Hokkaido summit, 2008).

Entretanto o percentual de redução de emissão de poluentes desejável, de acordo com cientistas, é de $70 \%$. Este valor seria suficiente para que o 
aquecimento fosse reduzido quase pela metade, evitando o derretimento das geleiras do Ártico e permitindo a preservação da pesca e da fauna (WASHINGTON et al., 2009).

O Brasil, em 2009, era responsável por 5\% das emissões mundiais de gases do efeito estufa (VIOLA, 2009), e de acordo com estimativas para 2004, tem cerca $75 \%$ de suas emissões oriundas das mudanças no uso da terra e da agricultura e pecuária (YU, 2004). No entanto, o Brasil tem vantagens para explorar nesse cenário, pois o país pode vir a se tornar um grande exportador de créditos de carbono através dos programas de Mecanismos de Desenvolvimento Limpo (MDL), bem como através do programa de Redução de Emissões de Desmatamento (REDD), além de possuir um programa de bio-combustíveis bem-sucedido.

As políticas ambientais mais discutidas mundialmente são os mercados de créditos de carbono (cap-and-trade) e os impostos às emissões. Alguns países desenvolvidos estão em processo avançado de discussão ou mesmo implementação dessas políticas. A União Europeia (UE) iniciou em 2005 um esquema de mercados de carbono, conhecido como European Union Greenhouse Gas Emission Trading System (EU ETS), o qual inclui a maioria dos países do bloco (REINAUD, 2004). Nos EUA, uma proposta de reduzir emissões, dentro do escopo do American Clean Energy and Security Act, foi aprovada na câmara dos deputados, mas rejeitada no senado. Tal proposta previa a implementação de um mercado de créditos de carbono semelhante ao europeu. O projeto pretendia reduzir as emissões de gases do efeito estufa em 58\% até 2030 em relação aos níveis de 2005. A partir de 2030, a redução deveria ser de $17 \%$ ao ano até 2050 (PALTSEV et al., 2009).

A adoção dessas políticas por alguns países deve gerar efeitos que se propagam para outras nações. Babiker e Jacoby (1999) discutem que a restrição em emissões nos países desenvolvidos aumenta o custo de manufaturados exportados aos países em desenvolvimento por encarecer as tecnologias intensivas em combustíveis fósseis, bem como diminuem a demanda mundial por tais combustíveis, reduzindo seus preços 
internacionais. O controle de emissões tende ainda a deprimir a atividade econômica nos países implementadores, diminuindo sua demanda por importações, o que afeta as vendas internacionais dos países em desenvolvimento. Essa combinação de mudanças nos preços e volumes comerciais pode favorecer algumas economias e prejudicar outras.

Dois aspectos importantes relacionados à adoção unilateral de políticas climáticas dizem respeito à mudança relativa no padrão de vantagem comparativa desses países e na possibilidade de vazamentos em emissões, que compromete a meta desejada de controle. Países que adotarem tais políticas tenderão a perder competitividade e reduzir suas participações nos mercados internacionais frente aos países que não adotarem restrições às emissões, por conta do encarecimento da produção local. Ainda, indústrias mais intensivas em emissões podem decidir por migrar suas plantas de produção para países que não possuem políticas climáticas, reduzindo assim a eficácia da política de redução em emissões, uma vez que tais mudanças dependem da concentração mundial de gases de efeito estufa. Tais aspectos têm sido considerados na formulação de políticas, como no caso do American Clean Energy Act of 2009, que prevê a cobrança de tarifas ou impostos compensatórios pelas emissões embutidas nas importações realizadas pelos Estados Unidos (US CONGRESS, 2009). Isso significaria a adoção de impostos compensatórios baseados no conteúdo de carbono (board carbon tax adjustment), que teriam o propósito de impedir a perda de competitividade pelas indústrias dos países que combatem as mudanças climáticas e evitar ou reduzir os vazamentos de emissões pelo deslocamento da produção de países que controlam suas emissões para países sem tais padrões (DISSOU E EYLAND, 2011).

O Brasil, por sua vez, oficializou na COP16, em 2010, compromissos voluntários de controle de suas emissões. O país se comprometeu a reduzir suas emissões entre $36,1 \%$ e $38,9 \%$ em relação às emissões projetadas para 2020 (BRASIL, 2009a). Cerca de 76\% das emissões de CO2 do país em 2005 foram causadas por mudanças do uso da terra e desmatamento, crescimento de 70\% em relação a 1990 (BRASIL, 
2009b). Os compromissos assumidos foram consolidados pela aprovação da Lei $\mathrm{n}^{\circ}$ 12.187, de dezembro de 2009, conhecida como Política Nacional sobre Mudança do Clima, que constitui estratégia permanente que deverá nortear a elaboração do Plano Nacional sobre Mudança do Clima, dos planos estaduais e de outros planos, programas, projetos e ações relacionadas com a mudança do clima.

Para cumprir com as metas de redução em emissões, estão previstas nesta lei as seguintes medidas: Redução de $80 \%$ do desmatamento na Amazônia Legal em relação à média verificada entre 1996 e 2005; Redução de $45 \%$ do desmatamento no Cerrado em relação à média verificada entre 1999 e 2008; Expansão da oferta hidrelétrica, da oferta de fontes alternativas renováveis, notadamente centrais eólicas, pequenas centrais hidrelétricas e bioeletricidade, da oferta de biocombustíveis e incremento da eficiência energética; Recuperação de 15 milhões de hectares de pastagens degradadas; Ampliação do sistema de integração lavoura-pecuária-floresta em 4 milhões de hectares; Expansão da prática de plantio direto na palha em 8 milhões de hectares; Expansão da fixação biológica de nitrogênio em 5,5 milhões de hectares de áreas de cultivo, em substituição ao uso de fertilizantes nitrogenados; Expansão do plantio de florestas em 3 milhões de hectares; Ampliação do uso de tecnologias para tratamento de 4,4 milhões de $m 3$ de dejetos de animais; e Incremento da utilização na siderurgia do carvão vegetal originário de florestas plantadas e melhoria na eficiência do processo de carbonização (BRASIL, 2009a).

Considerando as políticas climáticas em implementação na UE e em discussão nos EUA, bem como a Política e o Plano Nacional de Mudança do Clima, o objetivo do presente trabalho é avaliar os impactos que tais políticas ambientais possam ter sobre a economia brasileira, incluindo a possibilidade de cobrança de tarifas compensatórias com base no conteúdo de carbono pelos países desenvolvidos.

Para atingir o objetivo proposto, este trabalho faz uso de um modelo previamente construído de equilíbrio geral, o modelo Emissions Prediction and Policy Analysis(EPPA) (PALTSEV et al. 2005), para simular diferentes cenários de políticas climáticas. 
A respeito de trabalhos anteriores sobre o tema de políticas climáticas, diversos estudos, como os de Reilly e Paltsev (2006), Kasaharaet al. (2007) e Paltsev et al. (2008), procuram mensurar os impactos nos próprios países implementando as políticas. Quanto aos efeitos de tarifas compensatórias de carbono sobre terceiros países, podem-se destacar estudos como os de Babiker e Rutherford (2005) e Fischer e Fox (2007). No caso de estudos específicos sobre a economia brasileira, Tourinho, Motta e Alves (2003) bem como Silva e Gurgel (2012) estudaram o efeito da taxação de carbono no país. Já Feijó e Porto Jr (2009) mensuraram os impactos sobre o bem-estar da economia brasileira da implantação do Protocolo de Kyoto. Moreira e Giometti (2007) avaliaram os projetos de MDL a serem implantados nos países em desenvolvimento, enquanto Diaz e Schwartzman (2005) trataram das políticas de REDD, que são propostas para evitar o desmatamento e promover o reflorestamento. Lima (2011), por sua vez, estudou os impactos que políticas climáticas adotadas nos países desenvolvidos teriam sobre o Brasil, sem, contudo, abordar a questão dos possíveis efeitos de tarifas compensatórias de carbono (TCC).

Dessa forma, o presente trabalho busca acrescentar a essa literatura a mensuração dos impactos de políticas climáticas em países desenvolvidos sobre a economia brasileira, considerando a possibilidade de que barreiras comerciais sejam adotadas por tais países para compensar a perda de competitividade de suas empresas e evitar os vazamentos de carbono, bem como avalia a adoção de políticas climáticas pelo Brasil no âmbito do Plano Nacional sobre Mudança do Clima. 


\section{Metodologia}

Para atingir os objetivos da pesquisa, é necessário utilizar uma abordagem capaz de representar os diversos setores da economia responsáveis pelas emissões de gases de efeito estufa, bem como as relações entre esses setores e as interações entre os países através dos mercados mundiais. Modelos computáveis de equilíbrio geral são capazes de atender a essas necessidades, sendo uma ferramenta comum em estudos econômicos de políticas de amplo alcance na economia.

Dessa forma, escolheu-se o modelo EPPA, que é um modelo de equilíbrio geral para a economia mundial, que leva em conta dezesseis países e regiões, sendo desenvolvido pelo MIT Joint Program on the Science and Policy of Global Change (PALTSEV et al., 2005). O modelo foi construído e vem sendo aprimorado para projetar as emissões de gases causadores do efeito estufa de origem antropogênica e estimar os impactos econômicos de políticas climáticas.

Os modelos de equilíbrio geral são representados por interações entre diversos agentes que têm como objetivo a otimização de suas preferências e lucros. Assim sendo, estes interagem através dos mercados de bens e fatores de produção. Para obter o equilíbrio em um modelo de equilíbrio geral, é preciso que todas as variáveis endógenas (preços e quantidades) se ajustem de forma que os indivíduos, dadas suas restrições, não possam mais melhorar sua situação, alterando seu comportamento. Shoven e Whalley (1998) e Sadoulet e De Janvry (1995) apresentam mais detalhes sobre essa classe de modelos.

\subsection{O modelo EPPA}

O EPPA é um modelo de equilíbrio geral dinâmico recursivo, resolvido de 5 em 5 anos para a economia mundial, entre 2005 e 2100. Em cada período, funções de produção para cada setor da economia descrevem as 
combinações de capital, trabalho, terra, energia e insumos intermediários para gerar bens e serviços. O consumo é modelado pela presença de um indivíduo representativo que busca a maximização da utilidade pelo consumo de bens e serviços, enquanto os setores produtivos são guiados pela maximização do lucro.

No modelo EPPA, os setores de produção e consumo são representados por funções de produção aninhadas, de elasticidade de substituição constante (CES), incluindo funções Leontieff e Cobb-Douglas. A determinação dos ramos ou aninhamentos bem como das elasticidades depende das particularidades de cada setor, como discutido em PALTSEV et al. (2005 e 2008).

A agregação de setores e fatores primários do modelo procura representar os mercados de energia, incluindo o uso de recursos e tecnologias alternativas aos combustíveis fósseis. O modelo gera como resultados medidas de evolução e mudanças em variáveis econômicas como produto interno bruto, consumo agregado, nível de bem-estar, produção setorial, fluxo comercial, emissões de gases de efeito estufa e índices de preços em geral. Portanto, o modelo é uma ferramenta importante para a análise econômica dos efeitos das políticas climáticas. A Tabela 1 apresenta os países e regiões, setores e fatores primários de produção explicitamente representados no modelo. 
Tabela 1 - Países, Regiões e Setores do Modelo EPPA

\begin{tabular}{|c|c|c|}
\hline País ou Região & Setores & Fatores \\
\hline Desenvolvidos & Não-Energéticos & Capital \\
\hline Estados Unidos (EUA) & Agricultura - Culturas & Trabalho \\
\hline Canadá & Agricultura - Pecuária & Recursos de petróleo bruto \\
\hline Japão & Agricultura - Silvicultura & Recursos de Gás natural \\
\hline União Europeia (EUR) & Alimentos & Recursos de carvão \\
\hline Austrália e Nova Zelândia & Serviços & Recursos de petróleo mineral \\
\hline Federação Russa & Produtos intensivos em energia & Recursos nucleares \\
\hline \multirow[t]{3}{*}{ Leste Europeu } & Outros produtos industriais & Recursos hidroelétricos \\
\hline & Transporte industrial & Recursos eólicos e solares \\
\hline & Transporte urbano & Terra: Lavouras \\
\hline Em Desenvolvimento & De Energia & Terra: Pastagens \\
\hline Índia & Carvão & Terra: Florestas plantadas \\
\hline China & Petróleo bruto & Terra: Pastagens naturais \\
\hline Brasil (BRA) & Petróleo refinado & Terra: Florestas naturais \\
\hline Leste Asiático com maior renda & Gás natural & \\
\hline México & Elétrica: fóssil & \\
\hline América Latina & Elétrica: hidro & \\
\hline Oriente Médio & Elétrica: nuclear & \\
\hline África & Elétrica: solar e eólica & \\
\hline \multirow[t]{8}{*}{ Resto da Ásia } & Elétrica: biomassa & \\
\hline & Elétrica: CCGN* & \\
\hline & Elétrica: carvão com SCC** & \\
\hline & Elétrica: gás com SCC & \\
\hline & Elétrica: petróleo mineral & \\
\hline & Gás sintético & \\
\hline & Biocombustível de $2^{\text {a }}$ geração & \\
\hline & Etanol de cana-de-açúcar ${ }^{1}$ & \\
\hline
\end{tabular}

*CCGN: Ciclo combinado de gás natural **SCC:Sequestro e captura de carbono. ${ }^{1}$ apenas na região Brasil 
No presente trabalho, utiliza-se a versão 5 do modelo EPPA, que apresenta diversas sofisticações em relação à utilizada por Paltsev et al. $(2005)^{4}$

O EPPA é formulado como um problema de complementaridade mista em que as seguintes desigualdades precisam ser satisfeitas: Lucro zero em todos os setores produtivos, igualdade entre oferta e demanda em todos os mercados de bens e de fatores e igualdade entre renda e despesa para todos os agentes representados no modelo. Firmas e famílias seguem o comportamento de otimização, como preconizado pela teoria microeconômica. Para as firmas, a solução deste problema se dá quando elas escolhem um nível de produto e insumos, a fim de maximizar seus lucros, sujeitos às suas restrições tecnológicas. No modelo EPPA, assumese que a produção seja representada por tecnologias com elasticidade de substituição constante (CES), que, por apresentarem retornos constantes de escala, simplificam o problema da firma. Para solucionar o problema das famílias, o modelo considera, em cada região, que um agente representativo possui uma dotação inicial de fatores de produção e serviços, os quais podem ser vendidos ou alugados às firmas. Em cada período, este agente representativo escolhe seus níveis de consumo e poupança que maximizam sua função de bem-estar sujeita à sua restrição orçamentária.

As tecnologias de produção são representadas por funções CES aninhadas, que possibilitam mais possibilidades de substituição entre fontes de energia, fatores produtivos e outros insumo. A estrutura aninhada foi desenvolvida para permitir maior flexibilidade na

4 Algumas dessas sofisticações incluem: atualização da base de dados do equilíbrio inicial do modelo de 1997 para 2004, desagregação do setor agropecuário em três setores (culturas, pecuárias e silvicultura), desagregação da indústria de alimentos do setor de produção de outros bens, representação explícita de mudanças no uso da terra, seguindo a formulação de Gurgel et al. (2008), entre outras. Em relação a outras aplicações da versão 5 do modelo EPPA, como em Silva e Gurgel (2012) e Lima (2011), a presente versão representa a produção e consumo de etanol de cana-de-açúcar no Brasil bem como as relações de complementaridade da mistura deste combustível com o derivado de petróleo e de substituição entre eles pela presença de veículos flex-fuel na frota brasileira. 
calibragem de elasticidades, particularmente para os setores em que o custo de abatimento das emissões é mais sensível. Dados e informações econômicas e de engenharia são utilizados para determinar as possibilidades de substituição e as elasticidades. A Figura 1 exemplifica a estrutura aninhada dos setores de serviços, transportes, indústria intensiva em energia e a indústria de outros bens.

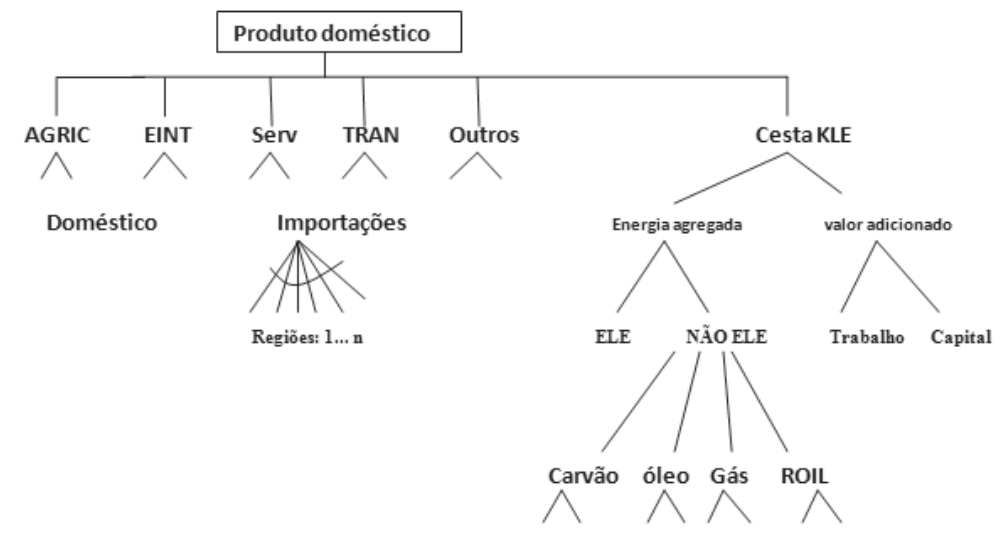

Figura 1 - Estrutura dos setores de serviços, transporte, intensivos em energia e Outros.

Fonte: Paltsev et al. (2005).

\subsection{Implementações de políticas}

O modelo EPPA tem uma variedade de opções para a especificação de políticas de controle de emissões. Impostos e insumos sobre combustíveis podem ser representados, bem como suas alíquotas podem ser fixadas para representar a composição de carbono dos diferentes tipos de combustíveis. Ainda podem ser impostas restrições quantitativas às emissões de gases de efeito estufa, com ou sem o comércio de permissões 
(ou créditos) de emissões ou carbono. Nesse caso, o modelo encontra endogenamente o preço a ser pago pelas permissões, com base na sua demanda. Os mercados de emissões podem ser especificados por região, setor e por gases do efeito estufa. Exportações e importações de licenças de emissões são contabilizadas juntamente com os demais fluxos comerciais, e o comércio destas permissões é contabilizado como parte da balança comercial. Controles de preço resultantes da solução do modelo com restrições sobre esses gases são reportados por toneladas de gás relevante (em contraposição a um preço equivalente de carbono). Quando o comércio de gases é permitido, a taxa de troca entre gases é baseada nos índices de Global Warming Potential. Com esta opção, reporta-se o preço equivalente de $\mathrm{CO}_{2}\left(\mathrm{CO}_{2}\right.$ Eq. $)$ associado à restrição quantitativa. Tal preço pode ser considerado equivalente ao nível do imposto de carbono que seria capaz de reduzir as emissões ao nível preconizado pela restrição quantitativa.

\section{Dados}

Os dados utilizados no estudo para alimentar e calibrar o modelo EPPA são oriundos do Global Trade Analysis Project - GTAP (DIMARANAN AND MCDOUGALL, 2002), um banco de dados que representa matrizes de insumo-produto para todos os países e regiões do mundo, consumo macroeconômico regional, produção e fluxos de comércio bilateral. Da Agência de Energia Internacional (IEA), são obtidos os dados a respeito da oferta e do consumo de energia dos países e regiões que fazem parte do modelo.

Os dados relativos aos gases que provocam o efeito estufa são obtidos da Agência de Proteção Ambiental Americana (EPA) e do banco de dados EDGAR (OLIVIER e BERDOWSKI, 2001), enquanto os dados relativos aos poluentes urbanos podem ser encontrados no banco de dados EDGAR. Em relação ao Brasil, além dos dados do país nas fontes mencionadas acima, foram consultadas bases de dados do IBGE sobre economia e uso da terra e do Ministério de Minas e Energia sobre a 
produção e uso de energia no país, utilizados para ajustar os dados iniciais do EPPA, quando necessário.

\section{Cenários simulados}

Os seguintes cenários foram simulados no modelo EPPA de forma a atingir os objetivos da pesquisa:

- BAU: Cenário de referência, sem políticas climáticas;

- EUA_UE: Implementação de políticas climáticas pelos Estados Unidos e União Europeia;

- EUA_UE_BCA: Implementação de políticas climáticas pelos Estados Unidos e União Europeia com imposição de tarifas de ajustamento de carbono a terceiros países. ${ }^{5}$

- EUA_UE_BRA: Implementação de políticas climáticas pelos Estados Unidos, União Europeia e Brasil.

- EUA_UE_BRA_BCA: Implementação de políticas climáticas pelos Estados Unidos, União Europeia e Brasil, com imposição de tarifas de ajustamento de carbono pelos EUA e UE.

- EUA_UE_BRA_SECT: Implementação de políticas climáticas pelos Estados Unidos, União Europeia e Brasil, sendo que o Brasil implementa metas de emissões diferenciadas por setores (Plano Nacional de Mudança Climática)

- EUA_UE_BRA_SECT_BCA: Implementação de políticas climáticas pelos Estados Unidos, União Europeia e Brasil, sendo que o Brasil implementa metas de emissões diferenciadas por setores (Plano Nacional de Mudança Climática), mas com a

5 As tarifas de ajustamento ao carbono são calculadas multiplicando-se o preço das permissões de carbono obtidas no cenário EUA_UEpelas emissões totais de gases de efeito estufa de cada setor e região no ano de 2010. O Apêndice apresenta os valores calculados para as tarifas bilaterais de ajustamento ao carbono aplicadas pelos EUA e pela UE. 
tarifa de ajustamento de carbono, com imposição de tarifas de ajustamento de carbono pelos EUA e UE.

Os níveis de cortes em emissões de gases de efeito estufa nos EUA e na UE assumem um comprometimento de redução de até $25 \%$ nas emissões até 2030, sendo cortes de cerca de 6\% em emissões em relação ao observado em 2005, a cada cinco anos, a partir de 2015. Esses cortes procuram refletir de forma simplificada as discussões de políticas nessas regiões. Os cortes são implementados através de mercados de carbono amplos em cada uma das regiões no sistema cap and trade, com possibilidade de trocas de permissões entre setores e gases diferentes.

O esquema de comércio de emissões da União Europeia (EU Emissions Trading Scheme - EU ETS) simula a terceira etapa de implementação do EU ETS, que propõe uma queda anual linear de $1,74 \%$ nas emissões a partir de 2013. O fator linear de 1,74\% usado na terceira etapa será aplicado até o ano de 2020, quando começará o quarto período de comércio (de 2021 a 2028). Posteriormente, essa taxa de redução deverá ser revisada até o ano de 2025. Como ainda não foram determinadas metas para os anos seguintes, será considerada a tendência de redução de 6 pontos percentuais a cada década até o ano de 2030, atingindo redução de 24 a 25\% em relação às emissões de 2005. Esta meta estaria em consonância com a proposta do G8 de redução de $50 \%$ nas emissões mundiais para o período em questão. Já no caso dos EUA, as reduções procuram refletir o debate em torno do assunto, com base na aprovação, em 26 de junho de 2009, na House of Representatives, do projeto de lei com o propósito de estabelecer um sistema de créditos de carbono para os EUA, similar ao EU ETS, contudo, barrado no Senado. O projeto previa reduzir as emissões de gases de efeito estufa durante o período de 2012 a 2050, sendo em 17\% em 2020, com base nos valores de 2005 . Já a proposta de $14 \%$ de reduções em 2020, mais próxima da meta de $12 \%$ assumida no presente estudo, foi defendida pela administração Obama. Tais propostas pretendiam chegar à meta de $80 \%$ de reduções para o ano de 2050. 
Nos Primeiros dois cenários de políticas, apenas EUA e UE aplicam medidas de corte das emissões dos gases do efeito estufa, sendo que o primeiro não levará em conta tarifas de ajustamento de carbono (BCA) nos países desenvolvidos e o segundo sim. Os cenários três e quatro incluem o Brasil no esforço de redução de emissões de GEE através de um mercado amplo de créditos de carbono, em que todos os setores da economia podem negociar a compra e venda desses créditos, com exceção das emissões oriundas de mudanças no uso da terra e desmatamento, sujeitas a metas específicas para evitar o excesso de créditos de carbono nos mercados. E analogamente aos cenários um e dois, o cenário três não contará com tarifas de ajustamento de carbono, e o quarto sim, aplicadas pelos países desenvolvidos às importações de bens oriundos de todos os países que não possuem políticas de redução de emissões. As emissões totais no Brasil devem ser reduzidas em cerca de 39\% até 2020 em relação às emissões do cenário de referência, procurando refletir as metas agregadas do Plano Nacional sobre Mudança do Clima (BRASIL, 2009a). De 2020 a 2030, considera-se a continuidade da política de redução em emissões atingindo $60 \%$ de redução em emissões em relação às emissões do cenário de referência.

Por fim, são simulados outros dois cenários como os cenários três e quatro, porém com a política de emissões brasileiras diferenciadas por setores, na tentativa de representar mais adequadamente o Plano Nacional sobre Mudança do Clima, pelo qual foi determinado um nível para reduções de emissões do desmatamento, outro para a agricultura e outro para o uso de energia. Nestes cenários, considera-se que a meta brasileira de corte de emissões em 38,9\% até 2020 deve ser atingida pelas reduções em emissões do desmatamento $(24,7 \%)$, da agricultura $(6,1 \%)$ e do uso de energia $(7,7 \%)$. Esses limites são impostos na forma de mercados setoriais de créditos de carbono, especificados para cada setor do modelo EPPA, sem possibilidade de compra e venda de créditos entre setores. Acredita-se que essa estratégia de implementação reflita melhor os custos e impactos das diferentes estratégias setoriais de cortes em emissões previstas na política brasileira, apresentadas brevemente na seção de introdução, uma vez que os mercados de emissões são considerados na 
literatura econômica a forma mais custo-efetiva de se atingir reduções, por gerarem ganhos de eficiência, adoção de tecnologias menos poluentes e substituição entre fontes de energia. Estes dois últimos cenários serão diferenciados pela sigla SECT. Sendo assim, espera-se mensurar para a economia brasileira os impactos dos três grupos de cenários simulado, quais sejam, de políticas climáticas nos países desenvolvidos, políticas climáticas também no Brasil, de cortes setoriais de emissões no Brasil bem como analisar os efeitos das tarifas compensatórias de carbono.

\section{Resultados}

O Gráfico 1 apresenta as emissões de gases de efeito estufa no Brasil nos diferentes cenários simulados. O modelo EPPA projeta emissões da ordem de quase 2.000 milhões de toneladas de $\mathrm{CO}_{2}$ Equivalente (Eq.) em 2010, no cenário de referência (BAU), o que representa uma leve queda em relação às emissões estimadas pelo Inventário Brasileiro de Emissões (BRASIL, 2009b) para o ano de 2005, de cerca de 2,19 bilhões de toneladas de $\mathrm{CO}_{2}$ Eq., devidas, principalmente, a menores emissões relacionadas às mudanças no uso da terra e ao desmatamento em 2010. No cenário de referência, o modelo ainda projeta emissões ligeiramente menores no ano de 2020, como consequência de mais reduções nas emissões provenientes do uso da terra, porém, um incremento nas emissões totais em 2030, que atingem a casa dos 2 bilhões de toneladas de $\mathrm{CO}_{2}$ Eq. As emissões maiores em 2030 em relação a 2010 são provenientes principalmente do crescimento das emissões causadas pelo uso de energia e de atividades industriais, identificadas como "Outros" no Gráfico 1. Nos cenários em que os EUA e a UE implementam políticas climáticas mas o Brasil não (cenários EUA_UE e EUA_UE_BCA), as emissões brasileiras em 2020 e 2030 permanecem praticamente as mesmas que no cenário de referência (BAU), indicando que políticas climáticas naqueles países têm efeitos desprezíveis sobre as emissões de gases de efeito estufa no Brasil, mesmo quando aqueles países aplicam barreiras tarifárias baseadas em carbono (cenários indicados pela sigla BCA). Esse resultado sugere que tais barreiras não são capazes de evitar 
os vazamentos em emissões provenientes do deslocamento de empresas e atividades produtivas de países com legislações ambientais mais rígidas para países que não limitam as emissões. Fortes reduções nas emissões brasileiros só serão observadas se o país adotar políticas climáticas ativas (cenários com a sigla BRA). Nesse caso, as maiores reduções se dão sobre as emissões oriundas de mudanças no uso da terra, como previsto no Plano Nacional de Mudança Climática. As emissões totais brasileiras são praticamente as mesmas quando o Brasil adota políticas climáticas, independentemente da aplicação ou não das tarifas compensatórias de carbono pelos países desenvolvidos.

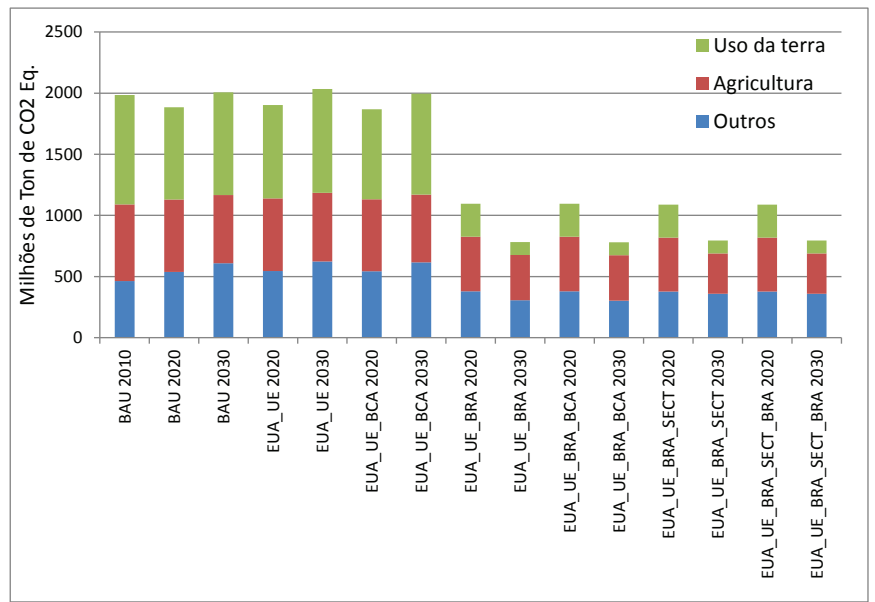

Gráfico 1 - Emissões brasileiras de gases de efeito estufa nos cenários simulados.

Fonte: Resultados da pesquisa.

O Gráfico 2 apresenta a evolução das emissões nos EUA, na UE e as emissões totais mundial. As emissões norte-americanas crescem no cenário de referência (BAU) entre 2010 e 2030 de 7,4 bilhões de toneladas de $\mathrm{CO}_{2}$ Eq. para 8,8 bilhões, enquanto as emissões europeias ficam estabilizadas em cerca de 5,5 bilhões de toneladas de $\mathrm{CO}_{2}$ Eq. no período. Nos cenários de políticas, contudo, essas regiões promovem 
cortes pronunciados em emissões. Fica nítido a partir desses gráficos que os cenários simulados pressupõem um maior esforço de redução de emissões pelos EUA em termos absolutos, apesar dos cortes percentuais similares aos implementados para a EU, calculados em relação às emissões observadas no ano de 2005. A redução absoluta em emissões menos pronunciada na UE é consequência da menor taxa de crescimento econômico desta região no cenário de referência, que resulta em um nível relativamente constante de emissões na ausência de políticas climáticas, bem como das iniciativas já estabelecidas naquele bloco para reduzir as emissões no futuro.

Já a trajetória de emissões mundiais de gases de efeito estufa é pouco afetada pelos cenários de políticas implementadas, reduzindo-se de 78 bilhões de toneladas de $\mathrm{CO}_{2}$ Eq., em 2030, no cenário de referência, para cerca de 71 bilhões quando os EUA, a UE e o Brasil adotam políticas climáticas. Esse resultado mostra que as políticas climáticas aplicadas apenas por um conjunto restrito de países diminui a taxa de crescimento mundial das emissões de gases do efeito estufa, porém, devido ao pronunciado crescimento econômico e de emissões esperado para os países em desenvolvimento, em especial China e na Índia, essas mesmas políticas não são capazes de reduzir as emissões mundiais de gases de efeito estufa a níveis recomendados pela comunidade científica mundial, revelando a necessidade de uma participação ativa de mais países para que o problema climático seja tratado adequadamente. 


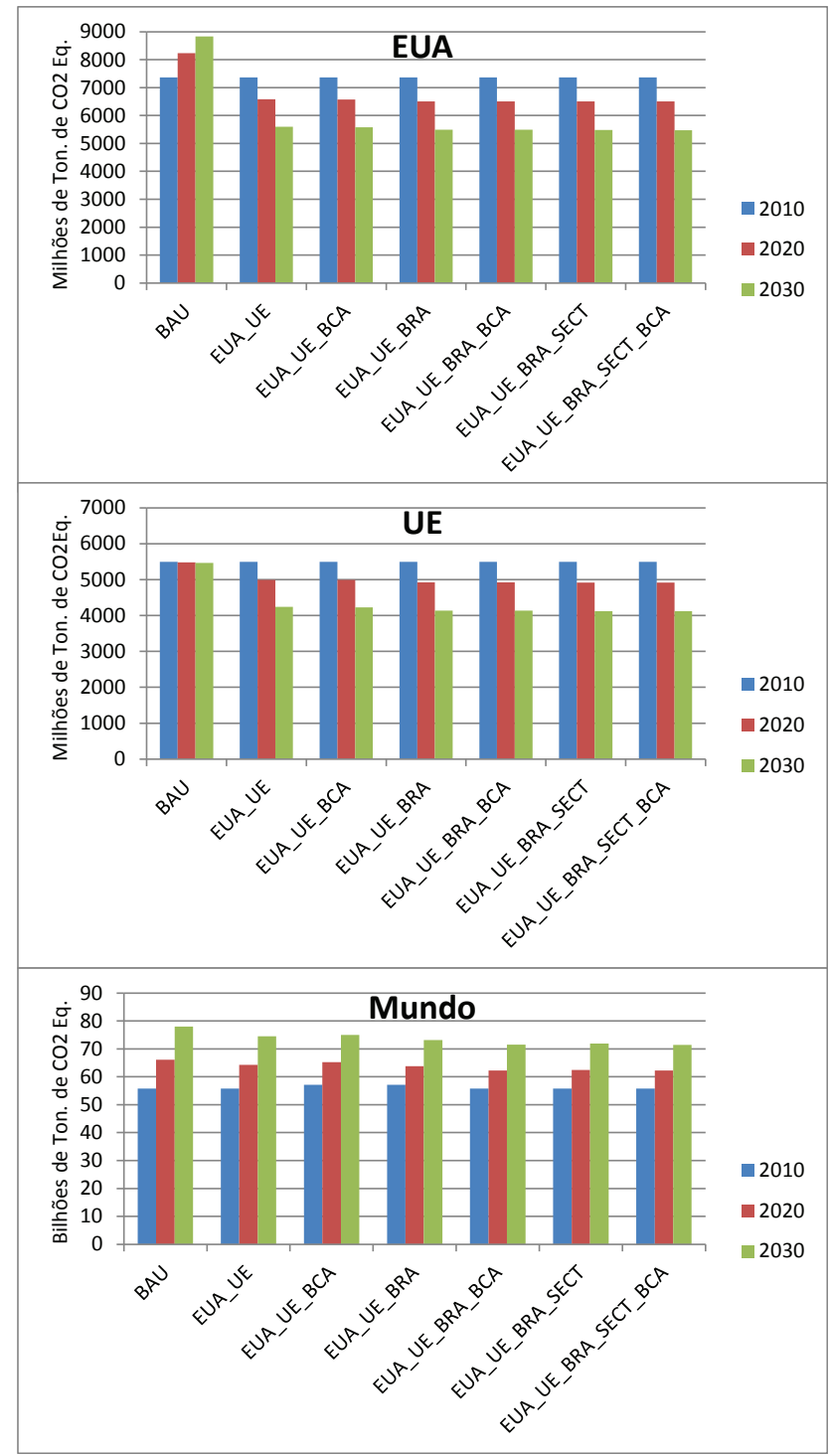

Gráfico 2 - Emissões de gases de efeito estufa nos EUA, UE e mundial nos cenários simulados.

Fonte: Resultados da pesquisa. 
A Tabela 2 apresenta as taxas anuais de crescimento do PIB para o Brasil, EUA, UE nos diferentes cenários simulados, calculadas em relação ao PIB no ano de 2010. Os resultados para o Brasil revelam que as políticas climáticas adotadas apenas pelos países desenvolvidos praticamente não afetam a taxa de crescimento do PIB brasileiro, mesmo sob a aplicação de tarifas compensatórias baseadas no conteúdo de carbono. A aplicação de políticas climáticas pelo Brasil, contudo, reduz as taxas de crescimento no país, apesar de essa redução não parecer expressiva. Como exemplo, a taxa anual de crescimento do PIB brasileiro cairia para 2,93\% ao ano em 2030 no cenário mais pessimista, enquanto no cenário de referência essa taxa seria de cerca de 3,13\%. Quando o Brasil aplica políticas climáticas ao mesmo tempo em que os países desenvolvidos aplicam tarifas compensatórias de carbono (BCA), seria esperado que o Brasil apresentasse maior acesso aos mercados daqueles países, uma vez que tais barreiras não são impostas a países que se esforçam para reduzir suas emissões. Contudo, os resultados indicam que esse maior acesso não se traduz em incrementos na taxa de crescimento do país, uma vez que os resultados dos cenários com as siglas BRA_BCA são praticamente os mesmos que dos cenários apenas com a sigla BRA. Percebe-se ainda que, ao longo do tempo, os cenários em que o Brasil aplica políticas climáticas setorialmente especificadas (cenários com a sigla SECT) tendem a resultar em quedas no PIB ligeiramente mais pronunciadas que os cenários em que o Brasil aplica um mercado amplo de carbono (cenários com a sigla BRA, mas sem a sigla SECT). Esse resultado indica que os cortes em emissões aplicados setorialmente trazem maiores custos de implementação que os gerados por um mercado de carbono amplo no país.

Já nos EUA e na UE, as políticas ambientais possuem efeitos menos pronunciados sobre a taxa de crescimento daquelas regiões, que já são menores no cenário de referência que as taxas de crescimento da economia brasileira, uma vez que aquelas economias são mais maduras e crescem principalmente pelo avanço tecnológico, enquanto o Brasil ainda tem grande potencial de crescimento por conta da acumulação de fatores produtivos, como capital físico e humano. As tarifas compensatórias de 
carbono não são capazes de alterar a queda na taxa de crescimento dos países desenvolvidos, mostrando a ineficiência desse instrumento em prevenir a perda de competitividade agregada e a migração de setores e fatores produtivos para regiões sem restrições às emissões de gases de efeito estufa. Os resultados de taxas de crescimento do PIB nos EUA e UE nos cenários em que o Brasil aplica políticas climáticas são exatamente os mesmos dos cenários de políticas climáticas aplicadas apenas pelos países desenvolvidos e, portanto, não foram apresentados na Tabela 2.

Tabela 2. Taxas anuais de crescimento do PIB em relação ao ano de 2010

\begin{tabular}{|c|c|c|c|c|c|}
\hline Região & Cenário & 2015 & 2020 & 2025 & 2030 \\
\hline \multirow{7}{*}{ Brasil } & BAU & 3,75 & 3,27 & 3,18 & 3,13 \\
\hline & EUA_UE & 3,75 & 3,27 & 3,18 & 3,12 \\
\hline & EUA_UE_BCA & 3,74 & 3,26 & 3,17 & 3,12 \\
\hline & EUA_UE_BRA & 3,69 & 3,10 & 3,01 & 2,96 \\
\hline & EUA_UE_BRA_BCA & 3,69 & 3,11 & 3,01 & 2,96 \\
\hline & EUA_UE_BRA_SECT & 3,66 & 3,12 & 3,00 & 2,93 \\
\hline & EUA_UE_BRA_SECT_BCA & 3,66 & 3,12 & 3,00 & 2,94 \\
\hline \multirow{4}{*}{ USA } & BAU & 3,03 & 2,73 & 2,62 & 2,62 \\
\hline & EUA_UE & 3,00 & 2,69 & 2,57 & 2,56 \\
\hline & EUA_UE_BCA & 3,00 & 2,69 & 2,57 & 2,56 \\
\hline & BAU & 1,90 & 1,90 & 1,86 & 1,84 \\
\hline EUR & EUA_UE & 1,90 & 1,88 & 1,83 & 1,80 \\
\hline
\end{tabular}

Fonte: Resultados da pesquisa.

O Gráfico 3 apresenta os resultados de mudanças em bem-estar advindos da aplicação das políticas climáticas, mensurados em relação ao cenário de referência. As mudanças em bem-estar podem ser interpretadas como as variações no nível agregado de satisfação das famílias decorrente das alterações no seu consumo e na sua renda, o que pode ser tomado 
como uma medida agregada dos custos das políticas sobre a economia do país. Os resultados para o Brasil sugerem que a aplicação de políticas climáticas apenas nos EUA e na UE, apesar de trazer resultados negativos para o país, implicam perdas de bem-estar bem modestas, de até $0,28 \%$ em 2030, na presença de tarifas compensatórias de carbono. É interessante notar que a aplicação de tarifas compensatórias baseadas no conteúdo de carbono pelos países desenvolvidos aumenta as perdas para a economia brasileira quando o Brasil não adota políticas climáticas (cenários EUA_UE e EUA_UE_BCA), mesmo que tais perdas sejam pouco expressivas. Já a implementação da política climática no Brasil tem efeitos modestos até o ano de 2020, atingindo cerca de $0,5 \%$ de perda em bem-estar. Contudo, essas perdas crescem consideravelmente até o ano de 2030 , podendo implicar quedas de ate $2,4 \%$, bem como passam a ter diferenças não desprezíveis entre os cenários de políticas considerados. Se o Brasil adotar políticas climáticas definidas setorialmente (cenários SECT), os custos para a sociedade são maiores, uma vez que diminuem as chances de distribuir maiores cortes em emissões para aqueles setores com menores custos de mitigação. Isso significa uma perda em bem-estar de até 0,5 pontos percentuais mais acentuada, ou $28 \%$ mais elevada, que nos cenários de mercados amplos de carbono no país. Outra diferença entre os cenários em que o Brasil aplica políticas climáticas, apesar de bem menos pronunciada, é a provocada pelas tarifas compensatórias de carbono dos países desenvolvidos. Quando aqueles países aplicam tais tarifas, as perdas de bem-estar no Brasil se reduzem ligeiramente, já que os produtos brasileiros não estariam sujeitos a essas barreiras se o Brasil adotar políticas climáticas. Isso significaria uma mudança a favor do Brasil em termos de vantagem comparativa, apesar de pouco expressiva em termos absolutos e relativos.

Nos EUA e na UE, as políticas climáticas impõem custos crescentes em termos de bem-estar em relação ao cenário de referência, contudo, bem menos expressivos que no Brasil. Nos EUA as quedas em bemestar atingem até $0,72 \%$ em 2030, enquanto na UE, chegam a $0,38 \%$. As perdas reduzem-se ligeiramente quando esses países aplicam tarifas 
compensatórias de carbono, indicando que esse instrumento, apesar de produzir efeitos na direção esperada, é pouco eficaz.

As perdas em bem-estar mais pronunciadas na economia brasileira em relação às economias norte-americana e europeia merecem mais discussões. A princípio, uma possível explicação para isso seriam os cortes em emissões relativamente mais expressivos no Brasil, como parecem sugerir os Gráficos 1 e 2. Contudo, o maior esforço de corte nas emissões brasileiras recai sobre a redução do desmatamento, sendo bem menos expressivos os cortes sobre as emissões da agricultura e dos demais setores (principalmente os relacionados ao uso de energia e processos industriais). Já nos países desenvolvidos, quase todos os esforços de redução em emissões recaem sobre o uso de energia e sobre a agricultura, uma vez que tais regiões hoje experimentam crescimento líquido em suas áreas de florestas. Isso significa que, em termos práticos, as políticas simuladas no presente estudo consideram cortes em emissões provenientes da agricultura e do consumo de energia mais expressivos nos EUA e na UE do que no Brasil. Como a redução nas emissões provenientes de mudanças no uso da terra é geralmente considerada de baixo custo, as perdas em bem-estar mais pronunciadas no Brasil devemse a maiores dificuldades, ou custos, de mitigar emissões na agricultura, na indústria e no uso de energia no país, em relação aos EUA e UE. No caso dos setores energéticos, esse resultado pode ser explicado pela matriz brasileira já ser bastante rica em fontes renováveis, mas com dificuldades crescentes de expandir a participação de tais fontes a baixo custo. 
Franklin Pedro França \& Angelo Costa Gurgel

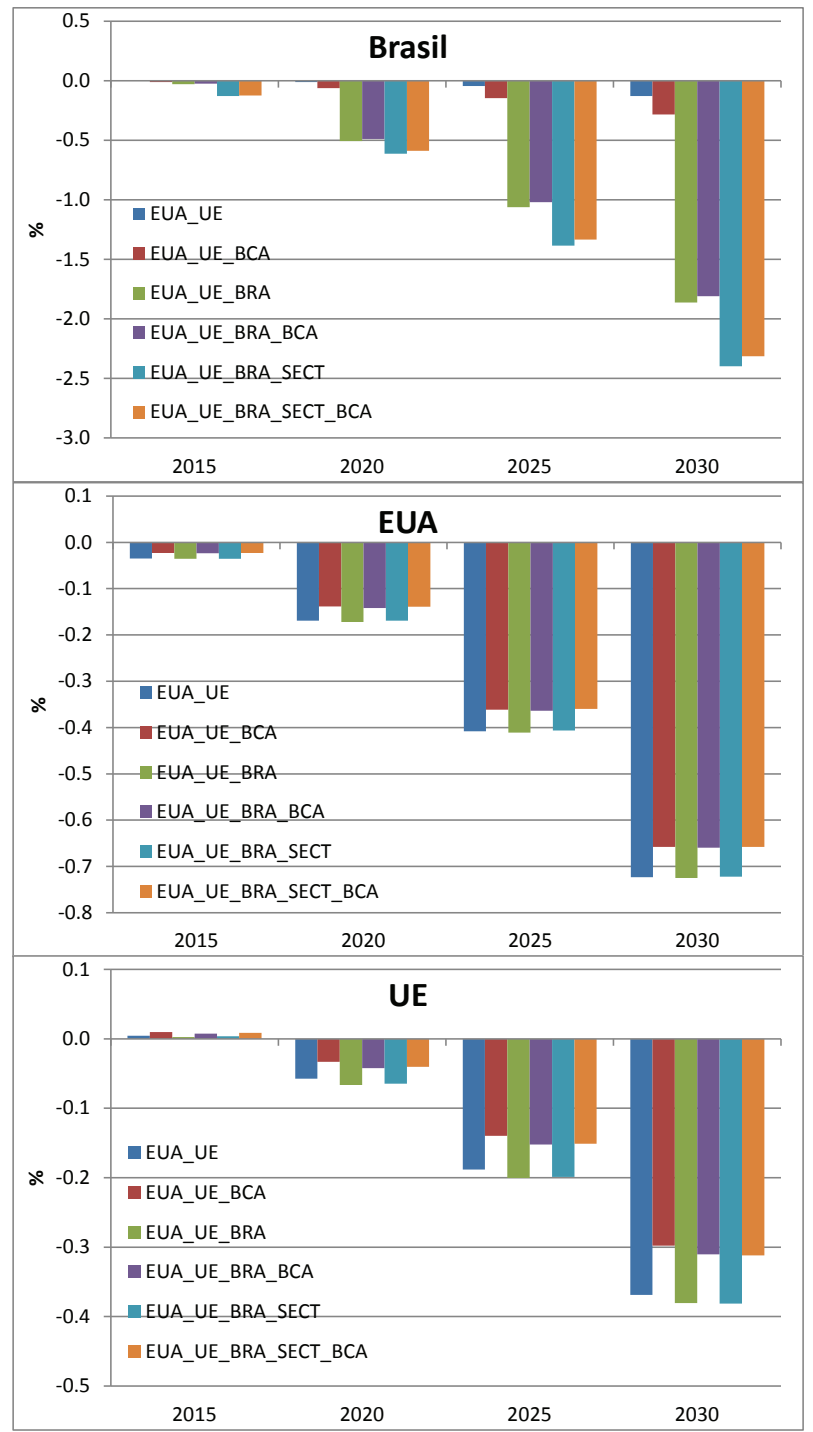

Gráfico 3 - Mudanças em Bem-Estar nos cenários de políticas climáticas em relação ao cenário de referência

Fonte: Resultados da pesquisa. 
Os Gráficos 4 e 5 ajudam a compreender as diferenças em perdas de bem-estar e custos de mitigação, uma vez que ilustram os preços a serem cobrados pelas permissões (ou créditos) de carbono de forma a atingir as reduções em emissões simuladas. O Gráfico 4 mostra que o preço das permissões de emissões nos EUA vão de US\$10/t de $\mathrm{CO}_{2}$ Eq. em 2015 a US\$ 80/t de $\mathrm{CO}_{2}$ Eq. em 2030. Já na UE, esses preços atingem o valor máximo de US\$ 38/t de $\mathrm{CO}_{2}$ Eq. em 2030, como consequência de um crescimento econômico menor e emissões estáveis no cenário de referência. No Brasil, o preço das permissões de carbono em 2020 deveria situar-se em torno de US\$38/t de $\mathrm{CO}_{2}$ Eq. em 2020 para atingir os objetivos do Plano Brasileiro de Mudança do Clima, caso fosse implementado um mercado de permissões de carbono amplo dentro do país. Esse preço se elevaria para US\$ 81 em 2030, caso os cortes em emissões fossem acentuados. Os preços das permissões de emissões representam os custos com os quais os setores da economia deveriam arcar para terem o direito de emitir uma tonelada de gases de efeito estufa e são consequência da competição e demanda por tais permissões, que têm sua oferta limitada de forma a garantir que o país ou região atinja o objetivo de redução em emissões ditado pela política climática. No caso da aplicação dos mercados amplos de carbono, aqueles setores com menores custos para reduzir emissões, seja via adoção de tecnologias menos poluidoras ou pela substituição e troca de insumos e fontes de energia, tendem a responder por mais cortes em emissões, tornando-se ofertadores líquidos de permissões de emissões, enquanto setores com menores capacidades de reduzir emissões se tornam demandantes líquidos de permissões. Os maiores preços das permissões de carbono no Brasil indicam dificuldades maiores para reduzir emissões na economia como um todo, seja pela adoção tecnológica ou pela troca de combustíveis fósseis por renováveis, em relação às economias americana e europeia, bem como pelo maior ritmo de crescimento econômico e de emissões projetado no cenário de referência, que significa maior demanda por permissões de emissões nos cenários de políticas. Vale notar, contudo, que os preços das permissões de emissões oriundas de mudanças no uso da terra, representadas no Gráfico 4 por BRA- Def., são bem menores 
que os do mercado de carbono, não passando dos US\$ 4/t de $\mathrm{CO}_{2} \cdot{ }^{6}$ Esse resultado está de acordo com a literatura, que afirma que os custos de redução em emissões provenientes de mudanças no uso da terra tendem a ser bem menores que os relacionados ao uso de energia fóssil e aos processos agropecuários e industriais. Dessa forma, a mitigação de emissões no Brasil via redução do desmatamento mostra-se bem mais custo-efetiva que a redução em emissões nos demais setores da economia.

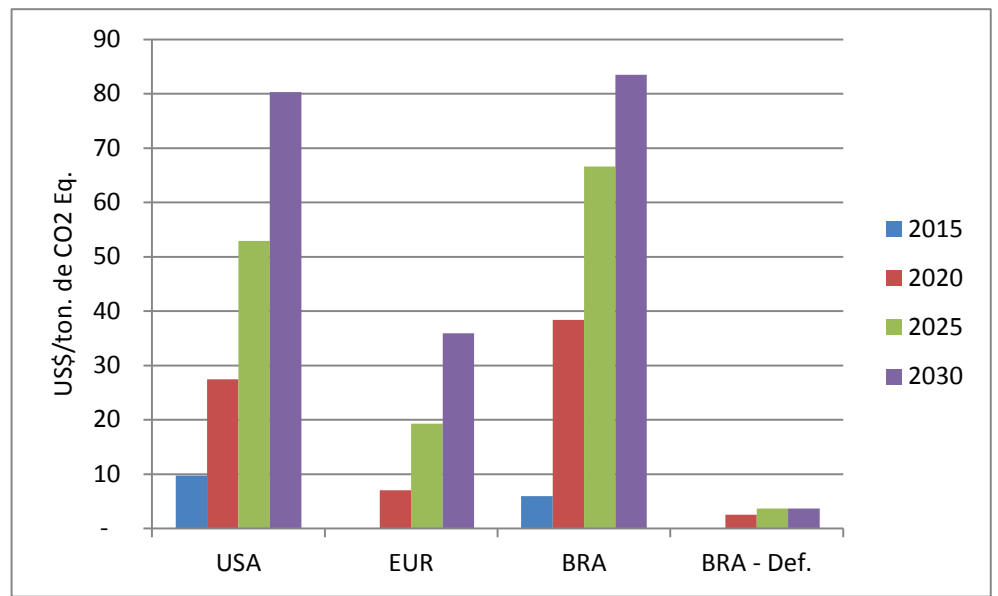

Grafico 4. Preço das permissões de emissões nos cenários de mercados de carbono regionais

Fonte: Resultados da pesquisa.

O Gráfico 5, por sua vez, apresenta os preços das permissões de carbono caso o Brasil implementasse cortes em emissões definidos setorialmente (cenários com a sigla BRA_SECT), que no presente estudo foram simulados como mercados de créditos de carbono restritos aos diferentes

6 Vale notar que os preços dos créditos de carbono proveniente de mudanças no uso da terra equivalem a um imposto médio de cerca de US\$ 750 por hectare no modelo EPPA, considerando o conteúdo de carbono médio associado aos diferentes tipos de vegetação natural no Brasil, baseados no Terrestrial Ecosystem Model do estudo de Melillo et al. (2009). 
setores, ou seja, que não permitem a compra e venda de permissões entre setores. Os setores de culturas e pecuária, por exemplo, são capazes de cumprir as metas de reduções em emissões a baixos custos em 2015, pagando, portanto, preços reduzidos por créditos setoriais de carbono naquele ano. Contudo, com a intensificação dos cortes em emissões no tempo, aumentam substancialmente os preços associados aos créditos de carbono capazes de forçar tais setores a atingir os cortes em emissões preconizados pela política. Já setores que geram produtos ricos em emissões, como o setor de refino do petróleo, acabam pagando preços relativamente baratos pelos créditos de carbono, uma vez que a demanda pelo seu produto é bastante reduzida na economia, o que permite atingir a meta de redução em emissões em grande parte pela queda na produção. $\mathrm{O}$ preço pago pela permissão de carbono em cada setor resulta da interação entre a oferta de créditos de carbono naquele setor, dada pela restrição quantitativa em emissões, e as forças de demanda por créditos de carbono, que, por sua vez, são determinadas pelo crescimento projetado para o setor no cenário de referência, pela intensidade setorial de emissões e pelas possibilidades e custos relativos de mudanças em tecnologias emissoras e fontes de energia. Setores com maiores intensidades de emissões e custos mais elevados para reduzi-las tendem a perder fatores produtivos para setores com maiores possibilidades de substituição de processos e insumos intensivos em emissões, gerando queda na produção do setor menos favorecido. 


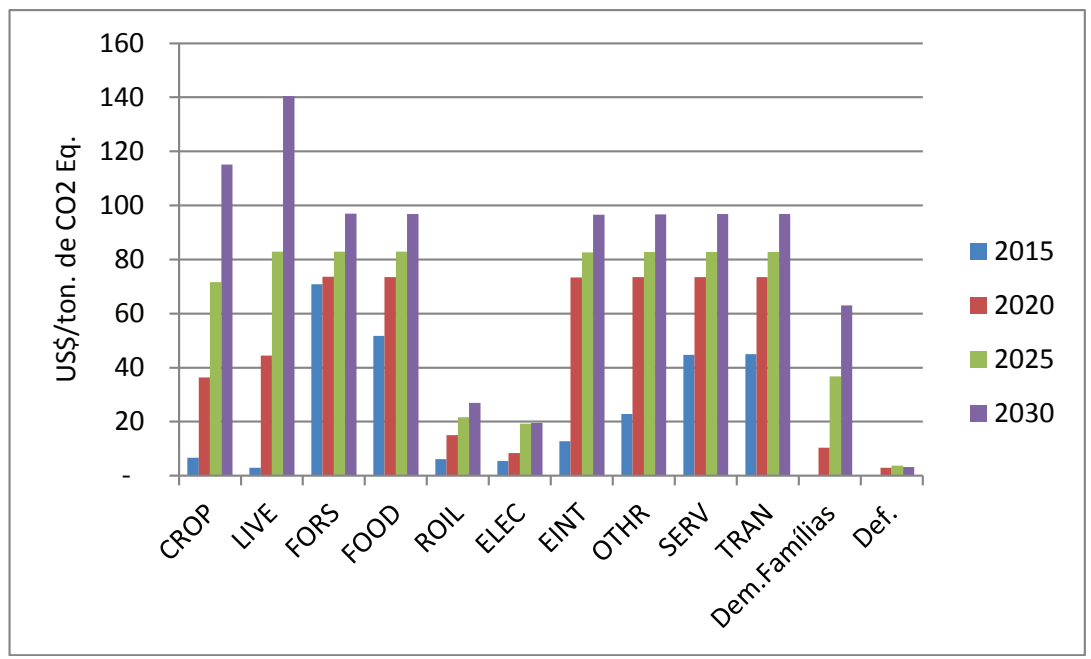

Gráfico 5 - Preços das permissões de emissões no Brasil sob mercados setoriais de carbono

Fonte: Resultados da pesquisa.

Percebe-se que o valor a ser pago por tonelada de emissões seria bastante diferente entre os setores, como consequência das diferentes oportunidades setoriais de mitigação e de substituição entre processos geradores de emissões e fontes de energia. Isso significa que as metas de redução em emissões definidas setorialmente devem promover mudanças consideráveis na competitividade dos setores, bem como competição intensa por recursos produtivos, por imporem custos diferenciados entre eles. Setores com maiores custos de mitigação tenderiam a perder fatores produtivos e insumos para setores com possibilidades mais baratas de adotar tecnologias limpas ou substituir fontes de energia fóssil por renováveis, levando a mudanças expressivas na composição do produto nacional. Esse resultado sugere que a definição de metas e cortes em emissões diferenciadas entre setores deve trazer ineficiências para a economia, por penalizar em demasia alguns setores e impedir o melhor aproveitamento das oportunidades mais baratas de mitigação na economia. 
O Quadro 1 mostra os impactos dos cenários de políticas climáticas sobre a produção dos diferentes setores no Brasil. Os setores de culturas agrícolas e pecuária aumentam a produção com as políticas ambientais quando estas são praticadas somente nos EUA e na EU (cenário EUA UE), sem a imposição de barreiras compensatórias ao carbono, uma vez que a produção se torna mais cara e diminui nesses países. Contudo, se forem aplicadas tarifas compensatórias de carbono, a produção brasileira sofre ligeira redução, de até $1 \%$, em relação à observada no cenário de referência, uma vez que uma parcela considerável das exportações brasileiras de produtos agrícolas é destinada aos EUA e à UE. Contudo, a produção agropecuária brasileira é bem mais afetada negativamente diante de uma política climática nacional, podendo se reduzir em até 29\% em relação à produção do cenário de referência (BAU) quando da aplicação de cortes em emissões definidos setorialmente. A queda na produção ocorre uma vez que a agropecuária é um dos maiores responsáveis pelas emissões de gases do efeito estufa. Nos cenários em que a política ambiental brasileira é setorial (SECT), o setor absorveria uma parcela ainda maior de responsabilidade na redução das emissões, o que nos demais cenários era compartilhado com outros setores da economia brasileira via mercado de créditos de carbono, gerando maiores quedas na produção. ${ }^{7}$

7 Vale notar que, quanto maiores e mais baratas forem as oportunidades de mitigação na agropecuária, menor tende a ser a queda na produção do setor. O Plano Nacional para Mudança do Clima prevê como estratégias de mitigação de emissões no setor a ampliação do plantio direto, da integração lavoura-pecuária e da fixação biológica de nitrogênio, a recuperação de pastagens e a adoção de tecnologias de tratamento de dejetos. Todas essas estratégias trazem custos para os produtores e cadeias agropecuárias. O modelo EPPA representa esses custos na forma de elasticidades de substituição entre as permissões de carbono e insumos de produção, como fatores produtivos e insumos intermediários. Tais elasticidades buscam refletir as inclinações de curvas de custo marginal de abatimento em emissões estimadas pela literatura. No caso do Brasil, existem poucas estimativas dessas curvas, o que aumenta o grau de incerteza dos resultados do modelo. Análises de sensibilidade mostram que as quedas na produção setorial da agropecuária brasileira se reduzem a menos da metade caso as elasticidades utilizadas aumentem de 0,02 para 0,04, valores razoáveis para países com o grau de tecnologia da agricultura brasileira. Trabalhos futuros sobre os custos de adoção das tecnologias previstas no Plano Nacional para Mudança do Clima e o potencial de redução de suas emissões devem permitir uma calibragem mais realista do modelo. 
Já o setor de silvicultura, que inclui a produção florestal e o extrativismo vegetal, é afetado positivamente pela política climática nacional, já que é bem menos intensivo em emissões que os setores de pecuária e culturas, aproveitando-se, portanto, de fatores produtivos específicos liberados quando da contração desses setores, como o recurso terra.

Os impactos sobre a indústria de alimentos seguem a mesma direção que os impactos sobre os setores agropecuários, uma vez que os principais insumos para a produção de alimentos são oriundos da agropecuária. Contudo, são menores em termos relativos, uma vez que outros insumos e produtos fazem parte dos custos de produção da indústria de alimentos.

Os setores intensivos em energia aumentam a produção com a introdução das políticas climáticas nos países desenvolvidos, por conta da perda de competitividade daqueles países. As tarifas compensatórias de carbono nos EUA e UE não alteram esse resultado, uma vez que as exportações brasileiras desses produtos são destinadas a outras regiões do mundo, ou passam a substituir os produtos dos países desenvolvidos em terceiros mercados. Ainda, como a matriz energética brasileira é relativamente mais limpa que a média mundial, as tarifas compensatórias aplicadas aos produtos brasileiros tendem a ser relativamente menores que as aplicadas a outros países. Sob a aplicação de uma política nacional de mudança climática, a produção brasileira se reduz em até $5 \%$ em relação ao cenário de referência. A aplicação de cortes setoriais em emissões traz mais perdas na produção até 2025 , por impedir a compra de créditos de emissões de setores com menores custos de abatimento. Contudo, a queda na produção é menos pronunciada a partir de 2030 quando do cumprimento de metas setoriais de redução em emissões, consequência do aumento da participação desse setor no total das emissões no cenário de referência, tornando o nível do corte setorial relativamente mais ameno neste do que em outros setores da economia. 
Quadro 1. Valor da produção setorial e variação percentual em relação ao cenário de referência

\begin{tabular}{|c|c|c|c|c|c|c|c|c|c|}
\hline \multirow[b]{2}{*}{ Setor } & \multirow[b]{2}{*}{ Cenário } & \multicolumn{4}{|c|}{ US\$ bilhões de US\$ (2004) } & \multicolumn{4}{|c|}{ Variação \% } \\
\hline & & 2015 & 2020 & 2025 & 2030 & 2015 & 2020 & 2025 & 2030 \\
\hline \multirow{7}{*}{ 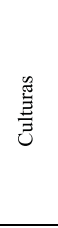 } & BAU & 53,2 & 58,7 & 64,4 & 70,5 & 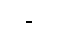 & & 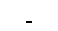 & \\
\hline & EUA_UE & 53,3 & 58,9 & 64,8 & 71,2 & 0,2 & 0,4 & 0,6 & 0,9 \\
\hline & EUA_UE_BCA & 53,2 & 58,4 & 63,8 & 69,8 & 0,0 & $-0,5$ & $-1,0$ & $-1,0$ \\
\hline & EUA_UE_BRA & 51,7 & 50,5 & 51,6 & 54,2 & $-2,8$ & $-14,0$ & $-20,0$ & $-23,1$ \\
\hline & EUA_UE_BRA_BCA & 51,7 & 50,6 & 51,7 & 54,6 & $-2,8$ & $-13,8$ & $-19,7$ & $-22,6$ \\
\hline & EUA_UE_BRA_SECT & 51,8 & 49,9 & 49,6 & 50,2 & $-2,6$ & $-15,0$ & $-23,0$ & $-28,8$ \\
\hline & EUA_UE_BRA_SECT_BCA & 51,8 & 50,0 & 49,7 & 50,2 & $-2,6$ & $-14,9$ & $-22,9$ & $-28,8$ \\
\hline \multirow{7}{*}{ 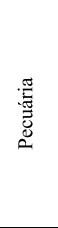 } & BAU & 21,4 & 23,4 & 26,0 & 28,9 & - & - & - & - \\
\hline & EUA_UE & 21,4 & 23,5 & 26,1 & 28,9 & 0,1 & 0,1 & 0,2 & 0,2 \\
\hline & EUA_UE_BCA & 21,4 & 23,4 & 25,9 & 28,8 & $-0,1$ & $-0,3$ & $-0,4$ & $-0,4$ \\
\hline & EUA_UE_BRA & 20,9 & 20,7 & 21,8 & 23,5 & $-2,5$ & $-11,5$ & $-16,3$ & $-18,5$ \\
\hline & EUA_UE_BRA_BCA & 20,9 & 20,7 & 21,8 & 23,5 & $-2,6$ & $-11,6$ & $-16,4$ & $-18,5$ \\
\hline & EUA_UE_BRA_SECT & 21,1 & 20,5 & 21,1 & 21,7 & $-1,7$ & $-12,6$ & $-19,1$ & $-24,9$ \\
\hline & EUA_UE BRA_SECT B & 21,1 & 20,5 & 21,1 & 21, & $-1,7$ & $-12,6$ & $-19,1$ & $-24,9$ \\
\hline \multirow{7}{*}{ 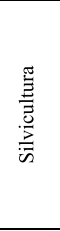 } & BAU & 0,8 & 0,9 & 1,0 & 1,2 & - & - & - & - \\
\hline & EUA_UE & 0,8 & 0,9 & 1,0 & 1, & 0,0 & $-0,3$ & $-0,4$ & $-0,4$ \\
\hline & EUA_UE_BCA & 0,8 & 0,9 & 1,0 & 1, & 0,0 & 0,8 & 0,7 & 0,5 \\
\hline & EUA_UE_BRA & 0,8 & 1,0 & 1,2 & 1,4 & $-0,5$ & 13,2 & 16,2 & 19,5 \\
\hline & EUA_UE_BRA_BCA & 0,8 & 1,0 & 1,2 & 1,4 & $-0,5$ & 13,1 & 16,1 & 19,1 \\
\hline & EUA_UE_BRA_SECT & 0,8 & 1,0 & 1,2 & 1, & $-0,8$ & 12,4 & 14,5 & 16,7 \\
\hline & EUA_UE_BRA_S & 0,8 & 1,0 & 1,2 & 1, & $-0,8$ & 12,3 & 14,4 & 16,5 \\
\hline \multirow{7}{*}{ 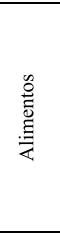 } & BAU & 117,2 & 127,8 & 141,6 & 156,8 & s. & & s. & \\
\hline & EUA_U & 117,3 & 127,9 & 141,7 & 15 & 0,0 & & & 0,0 \\
\hline & EUA_UE_BCA & 117,3 & 128,0 & 141,9 & & 0,0 &, 1 & 0,2 & 0,1 \\
\hline & EUA_UE_BRA & 115,1 & 116,7 & 123,5 & 133 & $-1,8$ & $-8,7$ & $-12,8$ & $-15,1$ \\
\hline & EUA_UE_BRA_B & 115,1 & 116,5 & 123,3 & 132 & $-1,8$ & $-8,8$ & $-12,9$ & $-15,3$ \\
\hline & EUA_UE_BRA_SECT & 115,8 & 115,5 & 120,2 & & $-1,3$ & $-9,6$ & $-15,1$ & $-20,2$ \\
\hline & EUA_UE_BRA_SECT_BCA & 115,7 & 115,5 & 120,1 & 125,0 & $-1,3$ & $-9,7$ & $-15,2$ & $-20,3$ \\
\hline \multirow{7}{*}{ 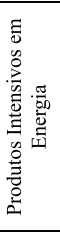 } & BAU & 210,5 & 235,1 & 268,5 & 308 & - & - & 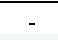 & - \\
\hline & EUA_UE & 210,9 & 236,4 & 271,3 & & 0,2 & 0,6 & , & 1,0 \\
\hline & EUA_UE_BCA & 210,9 & 236,5 & 271,4 & 311,4 & 0,2 & 0,6 & 1,1 & 1,0 \\
\hline & EUA_UE_BRA & 209,6 & 228,6 & 259,0 & 294,1 & $-0,4$ & $-2,8$ & $-3,5$ & $-4,7$ \\
\hline & EUA_UE_BRA_BCA & 209,6 & 228,5 & 259,0 & 293,8 & $-0,4$ & $-2,8$ & $-3,5$ & $-4,7$ \\
\hline & EUA_UE_BRA_SECT & 208,8 & 226,8 & 258,5 & 296,7 & $-0,8$ & $-3,5$ & $-3,7$ & $-3,8$ \\
\hline & EUA_UE_BRA_SECT_B & 208,8 & 226,9 & 258,6 & 296,8 & $-0,8$ & $-3,5$ & $-3,7$ & $-3,8$ \\
\hline \multirow{7}{*}{ 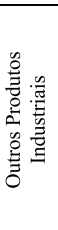 } & & 430,8 & 483,9 & 549,7 & 623 & - & - & - & - \\
\hline & EUA_UE & 430,6 & 483,3 & 548,5 & 621,5 & 0,0 & $-0,1$ & $-0,2$ & $-0,3$ \\
\hline & EUA_UE_BCA & 430,7 & 483,9 & 549,6 & 623,1 & 0,0 & 0,0 & 0,0 & 0,0 \\
\hline & EUA_UE_BRA & 432,7 & 493,7 & 562,9 & 631,4 & 0,4 & 2,0 & 2,4 & 1,3 \\
\hline & EUA_UE_BRA_BCA & 432,6 & 493,5 & 562,0 & 629,6 & 0,4 & 2,0 & 2,2 & 1,0 \\
\hline & EUA_UE_BRA_SECT & 433,1 & 493,2 & 559,8 & 630,6 & 0,5 & 1,9 & 1,8 & 1,2 \\
\hline & EUA_UE_BRA_SECT_BCA & 433,1 & 493,0 & 559,2 & 629,8 & 0,5 & 1,9 & 1,7 & 1,1 \\
\hline
\end{tabular}

Continua ... 
Quadro 1. (continuação) - Valor da produção setorial e variação percentual em relação ao cenário de referência

\begin{tabular}{|c|c|c|c|c|c|c|c|c|c|}
\hline \multirow[b]{2}{*}{ Setor } & \multirow[b]{2}{*}{ Cenário } & \multicolumn{4}{|c|}{ US\$ bilhões de US\$ (2004) } & \multicolumn{4}{|c|}{ Variação \% } \\
\hline & & 2015 & 2020 & 2025 & 2030 & 2015 & 2020 & 2025 & 2030 \\
\hline \multirow{7}{*}{ 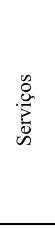 } & BAU & 607,8 & 706,1 & 828,9 & 972,6 & - & - & - & - \\
\hline & EUA_UE & 607,8 & 706,0 & 828,5 & 971,5 & 0,0 & 0,0 & 0,0 & $-0,1$ \\
\hline & EUA_UE_BCA & 607,8 & 706,1 & 828,7 & 971,9 & 0,0 & 0,0 & 0,0 & $-0,1$ \\
\hline & EUA_UE_BRA & 608,2 & 707,3 & 829,9 & 967,7 & 0,1 & 0,2 & 0,1 & $-0,5$ \\
\hline & EUA_UE_BRA_BCA & 608,2 & 707,3 & 829,6 & 966,8 & 0,1 & 0,2 & 0,1 & $-0,6$ \\
\hline & EUA_UE_BRA_SECT & 607,9 & 706,5 & 827,0 & 967,0 & 0,0 & 0,1 & $-0,2$ & $-0,6$ \\
\hline & EUA_UE_BRA_SECT_BCA & 607,9 & 706,4 & 827,0 & 966,8 & 0,0 & 0,0 & $-0,2$ & $-0,6$ \\
\hline \multirow{7}{*}{ 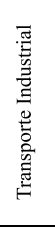 } & BAU & 53,6 & 61,1 & 71,2 & 82,9 & - & - & - & - \\
\hline & EUA_UE & 53,8 & 61,6 & 72,4 & 85,1 & 0,2 & 0,8 & 1,7 & 2,7 \\
\hline & EUA_UE_BCA & 53,7 & 61,4 & 71,8 & 83,9 & 0,2 & 0,4 & 0,9 & 1,2 \\
\hline & EUA_UE_BRA & 52,9 & 56,6 & 63,8 & 74,0 & $-1,4$ & $-7,3$ & $-10,4$ & $-10,7$ \\
\hline & EUA_UE_BRA_BCA & 52,9 & 56,5 & 63,8 & 74,0 & $-1,4$ & $-7,5$ & $-10,4$ & $-10,7$ \\
\hline & EUA_UE_BRA_SECT & 48,9 & 54,2 & 63,3 & 73,5 & $-8,8$ & $-11,3$ & $-11,1$ & $-11,2$ \\
\hline & EUA_UE_BRA_SECT_ & 48,9 & 54,2 & 63,3 & 73,5 & $-8,8$ & $-11,3$ & $-11,1$ & $-11,3$ \\
\hline \multirow{7}{*}{ 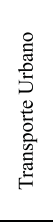 } & BAU & 56,3 & 65,4 & 76,1 & 88,2 & - & - & - & - \\
\hline & EUA_UE & 56,3 & 65,4 & 76,1 & 88,3 & 0,0 & 0,0 & 0,0 & 0,1 \\
\hline & EUA_UE_BCA & 56,3 & 65,4 & 76,0 & 88, & 0,0 & $-0,1$ & $-0,1$ & $-0,1$ \\
\hline & EUA_UE_BRA & 56,1 & 64,1 & 73,6 & 84,6 & $-0,3$ & $-2,0$ & $-3,2$ & $-4,1$ \\
\hline & EUA_UE_BRA_BCA & 56,1 & 64,1 & 73,6 & 84,7 & $-0,3$ & $-2,0$ & $-3,2$ & $-4,0$ \\
\hline & EUA_UE_BRA_SECT & 55,9 & 64,5 & 74,0 & 84,5 & $-0,7$ & $-1,5$ & $-2,8$ & $-4,2$ \\
\hline & EUA_UE_BRA_SECT_B & 55,9 & 64,5 & 74,0 & 84,5 & $-0,7$ & $-1,5$ & $-2,8$ & $-4,2$ \\
\hline \multirow{7}{*}{ : } & BAU & 0,2 & 0,2 & 0,2 & 0,2 & - & - & - & - \\
\hline & EUA_UE & 0,2 & 0,2 & 0,2 & 0,2 & $-1,5$ & $-3,6$ & $-5,1$ & $-7,2$ \\
\hline & EUA_UE_BCA & 0,2 & 0,2 & 0,2 & 0,2 & $-1,5$ & $-3,8$ & $-5,5$ & $-7,9$ \\
\hline & EUA_UE_BRA & 0,1 & 0,1 & 0,1 & 0,1 & $-10,4$ & $-36,9$ & $-47,7$ & $-54,5$ \\
\hline & EUA_UE_BRA_BCA & 0,1 & 0,1 & 0,1 & 0,1 & $-10,3$ & $-36,9$ & $-47,4$ & $-54,0$ \\
\hline & EUA_UE_BRA_SECT & 0,1 & 0,1 & 0,1 & 0,1 & $-12,4$ & $-26,6$ & $-34,6$ & $-37,1$ \\
\hline & EUA_UE_BRA_SECT_BCA & 0,1 & 0,1 & 0,1 & 0,1 & $-12,5$ & $-26,9$ & $-35,1$ & $-37,8$ \\
\hline \multirow{7}{*}{ 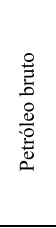 } & BAU & 24,5 & 25,6 & 26,8 & 27,4 & - & - & - & - \\
\hline & EUA_UE & 24,5 & 25,5 & 26,5 & 26,8 & $-0,1$ & $-0,2$ & $-1,1$ & $-2,4$ \\
\hline & EUA_UE_BCA & 24,5 & 25,5 & 26,5 & 26,8 & $-0,1$ & $-0,2$ & $-1,1$ & $-2,5$ \\
\hline & EUA_UE_BRA & 24,3 & 23,9 & 23,9 & 22,3 & $-1,1$ & $-6,5$ & $-10,8$ & $-18,7$ \\
\hline & EUA_UE_BRA_BCA & 24,3 & 24,0 & 24,1 & 22,7 & $-0,9$ & $-5,9$ & $-9,9$ & $-17,2$ \\
\hline & EUA_UE_BRA_SECT & 23,5 & 23,0 & 23,4 & 23,4 & $-4,0$ & $-9,9$ & $-12,6$ & $-14,7$ \\
\hline & EUA UE BRA SECT BCA & 23,6 & 23,2 & 23,8 & 24,0 & $-3,8$ & $-9,1$ & $-11,1$ & $-12,6$ \\
\hline \multirow{7}{*}{ 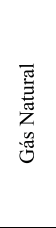 } & BAU & 1,8 & 2,0 & 2,4 & 2,9 & - & - & - & - \\
\hline & EUA_UE & 1,7 & 1,9 & 2,2 & 2,7 & $-1,9$ & $-3,2$ & $-5,5$ & $-10,0$ \\
\hline & EUA_UE_BCA & 1,7 & 1,9 & 2,2 & 2,6 & $-2,0$ & $-3,3$ & $-5,9$ & $-10,5$ \\
\hline & EUA_UE_BRA & 1,6 & 1,4 & 1,3 & 1,3 & $-7,3$ & $-28,6$ & $-45,2$ & $-57,1$ \\
\hline & EUA_UE_BRA_BCA & 1,6 & 1,4 & 1,3 & 1,3 & $-7,3$ & $-28,8$ & $-45,1$ & $-56,9$ \\
\hline & EUA_UE_BRA_SECT & 1,5 & 1,5 & 1,5 & 1,5 & $-12,0$ & $-24,7$ & $-38,2$ & $-47,7$ \\
\hline & EUA_UE_BRA_SECT_BCA & 1,5 & 1,5 & 1,5 & 1,5 & $-12,0$ & $-24,6$ & $-37,7$ & $-47,6$ \\
\hline
\end{tabular}

Continua ... 
Quadro 1 (continuação) - Valor da produção setorial e variação percentual em relação ao cenário de referência

\begin{tabular}{|c|c|c|c|c|c|c|c|c|c|}
\hline \multirow[b]{2}{*}{ Setor } & \multirow[b]{2}{*}{ Cenário } & \multicolumn{4}{|c|}{ US\$ bilhões de US\$ (2004) } & \multicolumn{4}{|c|}{ Variação \% } \\
\hline & & 2015 & 2020 & 2025 & 2030 & 2015 & 2020 & 2025 & 2030 \\
\hline \multirow{7}{*}{ 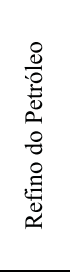 } & BAU & 44,5 & 46,6 & 49,1 & 51,3 & - & - & - & - \\
\hline & EUA_UE & 44,7 & 47,3 & 50,8 & 53,7 & 0,5 & 1,5 & 3,4 & 4,7 \\
\hline & EUA UE BCA & 44,6 & 46,8 & 49,6 & 51,8 & 0,2 & 0,4 & 1,1 & 0,9 \\
\hline & EUA_UE_BRA & 43,4 & 40,3 & 38,8 & 35,7 & $-2,5$ & $-13,7$ & $-20,9$ & $-30,5$ \\
\hline & EUA_UE_BRA_BCA & 43,5 & 40,5 & 39,4 & 36,5 & $-2,3$ & $-13,1$ & $-19,8$ & $-28,9$ \\
\hline & EUA_UE_BRA_SECT & 42,0 & 40,3 & 40,6 & 40,5 & $-5,7$ & $-13,5$ & $-17,2$ & $-21,0$ \\
\hline & EUA_UE_BRA_SECT_BCA & 42,1 & 40,6 & 41,2 & 41,4 & $-5,5$ & $-12,9$ & $-16,1$ & $-19,4$ \\
\hline \multirow{7}{*}{ 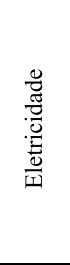 } & BAU & 39,8 & 42,3 & 44,9 & 48,2 & - & - & - & - \\
\hline & EUA_UE & 39,9 & 42,4 & 45,2 & 47,8 & 0,1 & 0,3 & 0,7 & $-0,8$ \\
\hline & EUA_UE_BCA & 39,9 & 42,4 & 45,1 & 47,7 & 0,1 & 0,3 & 0,6 & $-0,9$ \\
\hline & EUA_UE_BRA & 39,4 & 39,9 & 41,9 & 44,2 & $-1,0$ & $-5,6$ & $-6,6$ & $-8,2$ \\
\hline & EUA_UE_BRA_BCA & 39,4 & 39,9 & 41,9 & 44,2 & $-1,0$ & $-5,7$ & $-6,6$ & $-8,2$ \\
\hline & EUA_UE_BRA_SECT & 39,4 & 41,2 & 43,0 & 46,1 & $-1,0$ & $-2,5$ & $-4,2$ & $-4,3$ \\
\hline & EUA_UE_BRA_SECT_BCA & 39,4 & 41,2 & 43,0 & 46,0 & $-1,1$ & $-2,5$ & $-4,2$ & $-4,4$ \\
\hline \multirow{7}{*}{ 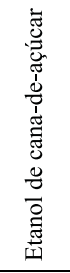 } & BAU & 4,1 & 4,3 & 4,8 & 5,2 & - & - & - & - \\
\hline & EUA_UE & 4,1 & 4,3 & 4,7 & 5,1 & $-0,1$ & $-0,2$ & $-0,7$ & $-1,8$ \\
\hline & EUA_UE_BCA & 4,1 & 4,3 & 4,7 & 5,1 & $-0,1$ & $-0,2$ & $-0,7$ & $-1,9$ \\
\hline & EUA_UE_BRA & 4,2 & 4,8 & 5,5 & 5,7 & 2,3 & 11,9 & 15,9 & 11,2 \\
\hline & EUA_UE_BRA_BCA & 4,2 & 4,8 & 5,5 & 5,7 & 2,3 & 12,1 & 15,9 & 11,3 \\
\hline & EUA_UE_BRA_SECT & 4,0 & 4,1 & 4,7 & 5,1 & $-2,4$ & $-5,5$ & $-2,3$ & $-1,1$ \\
\hline & EUA_UE_BRA_SECT_BCA & 4,0 & 4,1 & 4,7 & 5,1 & $-2,3$ & $-5,4$ & $-1,7$ & $-0,7$ \\
\hline \multirow{7}{*}{ 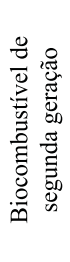 } & BAU & 0,0 & 0,0 & 0,0 & 0,0 & - & - & - & - \\
\hline & EUA_UE & 0,0 & 0,0 & 0,0 & 0,0 & & & & \\
\hline & EUA_UE_BCA & 0,0 & 0,0 & 0,0 & 0,0 & & & & \\
\hline & EUA_UE_BRA & 0,0 & 0,0 & 1,8 & 8,5 & & & & \\
\hline & EUA_UE_BRA_BCA & 0,0 & 0,0 & 2,1 & 9,2 & & & & \\
\hline & EUA_UE_BRA_SECT & 0,0 & 2,8 & 5,0 & 8,1 & & & & \\
\hline & EUA_UE_BRA_SECT_BCA & 0,0 & 2,8 & 5,1 & 8,2 & & & & \\
\hline
\end{tabular}

Fonte: Resultados da pesquisa.

Os demais setores industriais (outros produtos industriais) experimentam quedas inexpressivas na produção quando o país não aplica políticas climáticas enquanto os EUA e UE as implementam. Tarifas de ajustamento de carbono revertem esse resultado, uma vez que a baixa intensidade de carbono do setor o favorece com tarifas relativamente menores que as 
sofridas pelos setores mais intensivos em carbono, conferindo alguma vantagem comparativa. Quando o Brasil aplica políticas climáticas, a produção deste setor é afetada positivamente, porém de maneira pouco expressiva, uma vez que esses setores são pouco intensivos em emissões oriundas do uso de energia fóssil, sofrendo, portanto, menores custos que os demais, atraindo fatores produtivos antes utilizados por eles.

Já o setor de serviços quase não apresenta mudanças na sua produção nos cenários de políticas climáticas em relação ao cenário de referência. Os maiores impactos negativos não passam de $0,6 \%$ no ano de 2030 , seguindo a queda geral do produto na economia.

O setor de serviços de transportes industriais, por sua vez, é impactado negativamente pelas políticas climáticas no país, com quedas de até $11 \%$ no seu nível de atividade. Dois fatores contribuem para este resultado, sendo o primeiro relacionado à dependência deste setor no uso de combustíveis fósseis derivados do petróleo e o segundo relacionado à queda na atividade econômica do país, o que representa uma menor demanda por serviços de transportes, insumo necessário em praticamente todos os demais setores da economia. Deve-se salientar que a possibilidade de substituição da gasolina por biocombustíveis no setor de transporte industrial é limitada, uma vez que apenas biocombustíveis avançados (de segunda geração) são considerados substitutos possíveis, pois a frota de transporte industrial inclui os veículos de transporte rodoviário pesado, bem como os equipamentos de transporte aéreo, ferroviário e hidroviário, enquanto não considera os veículos rodoviários de médio e pequeno porte de uso comum pelas famílias (setor de transporte urbano no modelo). Os combustíveis avançados, por outro lado, só se tornam disponíveis a custos competitivos e em larga escala após alguns anos e em cenários específicos de políticas climáticas, como será discutido posteriormente. Essa disponibilidade mais tardia desse tipo de biocombustível ajuda a explicar a estabilização das quedas no fornecimento dos transportes industriais em níveis próximos a 10\% nos cenários de políticas climáticas no Brasil, uma vez que esse combustível renovável passa a substituir os derivados de petróleo diante de restrições mais severas às emissões de gases de efeito estufa na economia. 
O setor de transporte urbano representa os gastos das famílias com serviços de transportes fornecidos por veículos próprios. Esses gastos incluem os incorridos na compra de automóveis, combustível, peças e serviços de reparo, seguros e outros relacionados. O Quadro 1 evidencia que os cenários de imposição de políticas climáticas no Brasil afetam negativamente o suprimento de serviços de transporte urbano no país, que chega a ser $4 \%$ menor que no cenário de referência. Tal queda se deve ao encarecimento dos diversos componentes deste tipo de serviço quando da necessidade de pagamento pelas emissões geradas no processo de produção desses componentes, bem como do insumo combustível, na sua maioria, de origem fóssil. Ainda, a queda na renda agregada da economia contribui para a redução do consumo total das famílias. Nota-se, contudo, que a redução na oferta de transporte urbano é bem menos expressiva que a queda na produção de serviços de transportes industriais, consequência da capacidade de substituição de combustíveis fósseis por biocombustíveis de primeira geração (etanol) nos primeiros anos de simulação do modelo e de segunda geração nos demais anos.

Os setores de produção de energia fóssil (COAL, GAS e OIL) são os que sofrem maiores impactos negativos em produção nos diferentes cenários simulados. Quando apenas os EUA e a UE aplicam políticas climáticas, a queda na produção desses setores no Brasil está relacionada à queda no preço mundial desses produtos, uma vez que o menor consumo naqueles países desenvolvidos afeta negativamente sua demanda mundial. Isso significa aumento nas importações brasileiras e/ou redução nas exportações, com consequente queda na produção doméstica. Os efeitos negativos mais pronunciados sobre tais setores, contudo, são observados nos cenários de políticas climáticas no Brasil, como seria esperado. Diante da imposição de cortes em emissões, a demanda por esse tipo de energia se reduz consideravelmente, seja pela substituição delas por fontes renováveis, seja pela adoção de tecnologias mais eficientes no uso de energia, ou seja ainda pela queda na produção dos setores consumidores deste tipo de energia. As maiores quedas em produção são observadas nos setores de carvão e de gás natural, atingindo $54 \%$ e $57 \%$, respectivamente. As quedas menos expressivas no setor de 
extração de petróleo revelam uma maior dependência da matriz energética brasileira no uso desta fonte de energia. Ainda, os resultados negativos dos cenários de políticas setoriais (SECT) são, em geral, ligeiramente menos expressivos que do cenário de mercado amplo de carbono, indicando uma menor possibilidade de substituição dos combustíveis fósseis por fontes alternativas na presença de metas de cortes em emissões restritas setorialmente.

Os resultados para o setor de refino do petróleo seguem a direção dos resultados do setor de extração de petróleo, com exceção dos observados nos cenários de políticas climáticas apenas nos EUA e na EU, que geram pequenos aumentos na produção de petróleo refinado no país. Esse resultado indica que a queda no preço internacional do petróleo cru, consequente da menor demanda mundial por este produto, torna esse insumo mais barato para a indústria brasileira de refino, que aumenta sua produção.

A geração de eletricidade no país experimenta pequenos aumentos em produção até 2025 nos cenários de políticas climáticas apenas nos países desenvolvidos, decorrentes do barateamento das fontes de energia fóssil, usadas em proporções modestas na produção de energia elétrica no país. Contudo, em 2030, a produção de eletricidade apresenta ligeira queda, tanto por conta da menor produção de combustíveis fósseis, mas também e mais importante, pela redução na produção de importantes setores demandantes de eletricidade, como o setor de serviços, e do nível de atividade e consumo geral da economia, como apresentados nos resultados de PIB e bem-estar. As quedas na produção de eletricidade são bem mais expressivas quando o Brasil adota políticas climáticas, atingindo até $8 \%$ de redução em 2030. Como a maior parte da geração de eletricidade no país é proveniente de energia hidrelétrica, que é uma fonte renovável, as quedas em produção são bem menos expressivas que as observadas para os setores de energia fóssil, sendo devidas principalmente à redução no consumo dos setores industriais, de serviços e das famílias, como consequência da internalização dos custos ambientais associados às emissões de gases de efeito estufa nos diferentes 
setores econômicos. Os maiores impactos são observados nos cenários de mercados amplos de carbono no país e estão associados a um aumento na participação das fontes fósseis na geração de eletricidade ao longo do tempo e às quedas mais pronunciadas no consumo dos setores intensivos em energia nesses cenários.

Os dois últimos setores energéticos de interesse são os de produção de biocombustíveis, quais sejam, o de etanol da cana-de-açúcar e o de biocombustíveis de segunda geração. O Quadro 1 mostra que a imposição de políticas climáticas nos EUA e na UE afeta negativamente a produção de etanol, apesar de esses efeitos serem pequenos, de até -2\% em 2030. Esse efeito é consequência do aumento da oferta de combustíveis oriundos do refino do petróleo, que se tornam mais baratos diante da queda da demanda dos EUA e países europeus. Vale ressaltar que se assume no modelo a não comercialização internacional de biocombustíveis, devido às incertezas atuais sobre o desenvolvimento de um mercado internacional para eles. Quando o Brasil adota políticas climáticas na forma de um mercado amplo de carbono, a produção de etanol apresenta aumentos substanciais, de até $16 \%$ em relação ao cenário de referência em 2025, por conta da possibilidade de substituir a gasolina no setor de transporte urbano, contribuindo para o abatimento das emissões de forma relativamente barata. Contudo, diante de políticas climáticas setorialmente definidas, a produção de etanol de cana-de-açúcar cai, uma vez que o elevado custo de abatimento no setor de transporte industrial, que não utiliza o etanol tradicional de cana, estimula o desenvolvimento precoce dos biocombustíveis de segunda geração, permitindo que ele se torne competitivo mais cedo, podendo também ser utilizado para substituir a gasolina no setor de transporte urbano. Como no Brasil a segunda geração de biocombustíveis provavelmente será baseada, ao menos em parte, no uso do bagaço e da palha da cana-de-açúcar para geração de etanol, a queda na produção de etanol de cana-de-açúcar não significa comprometimento na produção desse combustível, apenas mudança na nomenclatura do produto. $\mathrm{O}$ aumento na produção de biocombustíveis, considerando em conjunto o etanol de cana-de-açúcar e o de segunda geração, chega a $200 \%$ da produção do cenário de referência 
em 2030, no cenário EUA_UE_BRA_BCA, e a 157\%, no cenário EUA UE_BRA_SECT. Esses valores refletem as elevadas possibilidades de redução em emissões no setor de transportes associados ao crescimento e desenvolvimento da produção de biocombustíveis no país.

\section{Conclusões}

O presente trabalho simula e analisa os efeitos que políticas climáticas aplicadas pelos países desenvolvidos (EUA e UE) e pelo Brasil teriam sobre a economia brasileira e sobre o total de emissões no mundo e naqueles países, em um horizonte futuro de 20 anos. Para tal, utiliza um modelo de equilíbrio geral da economia mundial, construído para projetar emissões de gases de efeito estufa oriundas de diferentes atividades econômicas e simular políticas de redução dessas emissões.

Os resultados permitem concluir que a trajetória de emissões globais ao longo do tempo é pouco afetada pelas políticas simuladas, o que significa a necessidade de maior participação e cooperação global para estabilizar emissões e reduzir os riscos das mudanças climáticas. A implementação de mercados de carbono gera custos que reduzem a taxa de crescimento dos países e queda do bem-estar. Nos EUA e na UE, as perdas de bemestar atingem cerca de $0,7 \%$ e $0,4 \%$, respectivamente, em 2030 , o que são custos modestos considerando os cortes em emissões simulados de $25 \%$ em relação às emissões observadas em 2005. O Brasil sofreria perdas de até de $0,3 \%$ em bem-estar em 2030 caso não aplique políticas climáticas, como consequência das mudanças no comércio mundial e das tarifas compensatórias de carbono impostas por aqueles países. Contudo, quando o país impõe cortes em suas emissões, os custos de bem-estar podem atingir até 2,4\% em 2030. Apesar de esse custo ser baixo, ele é relativamente mais expressivo que nos EUA e na EU, o que sugere menores possibilidades de adoção de tecnologias de baixas emissões e de substituição de fontes de energia fósseis por renováveis, uma vez que a matriz energética brasileira já é relativamente abundante no uso de fontes livres de emissões. 
A aplicação de tarifas compensatórias de carbono pelos países desenvolvidos, apesar de dobrarem a perda de bem-estar no Brasil quando o país não adota política climática, afeta pouco a maioria dos setores brasileiros. A agropecuária e a produção e alimentos são os setores mais prejudicados por tais barreiras comerciais. Contudo, essas barreiras comerciais são pouco eficientes em evitar os vazamentos em emissões e a perda de competitividade daquelas economias. Devido ao efeito não desprezível de distorção nos mercados internacionais que tal instrumento provoca, ele deve encontrar forte oposição por parte dos países em desenvolvimento nos fóruns internacionais, como a Organização Mundial de Comércio, quanto à sua aplicação.

Os efeitos negativos das tarifas compensatórias de carbono sobre a economia brasileira são bem menos expressivos que os efeitos da adoção de políticas climáticas pelo país. A redução nas emissões do desmatamento apresenta menores custos de mitigação, o que confirma a principal estratégia da política em implementação no país. Os cortes em emissões definidos serialmente, contudo, mostram-se bem menos custo-efetivos que outras estratégias mais desejáveis, como os mercados de carbono. Isso ocorre uma vez que as metas setoriais não garantem que as opções mais baratas de mitigação sejam aproveitadas, impedindo que setores com menores custos de abatimento de emissões respondam com mais contribuições para a meta nacional, ou mesmo que recebam créditos negociáveis e aufiram lucro pela comercialização desses créditos.

Os resultados setoriais mostram que os setores de produção e uso de energia fóssil e a agropecuária seriam os mais prejudicados pela política climática doméstica. O grande potencial de mitigação pela produção e uso de biocombustíveis no Brasil é confirmado pelo presente estudo, apesar de esse potencial não impedir a queda na produção e consumo do setor de transportes. A implementação de um mercado amplo de emissões no país permitiria menores custos para os setores brasileiros que os cortes em emissões implementados setorialmente.

Por fim, apesar de os resultados do estudo sugerirem ser mais desejável enfrentar barreiras comerciais baseadas em conteúdo de carbono impostas 
pelos países desenvolvidos que mitigar emissões domesticamente, essas barreiras são ineficientes para evitar emissões e impedir a perda de competitividade dos países desenvolvidos. Os custos aqui estimados associados às políticas climáticas são relativamente modestos e devem trazer o benefício de reduzir emissões e seus efeitos indesejáveis sobre a temperatura do planeta, benefício esse não estimado no presente estudo pelas dificuldades e incertezas associadas a tal mensuração. De outra forma, diante da necessidade de se internalizar os efeitos negativos das emissões antrópicas, melhor fazê-lo de forma eficiente e com menores custos, que no presente trabalho, são obtidos, no caso do Brasil, primeiro, pela redução nas emissões do desmatamento, e segundo, pela aplicação de mercados amplos de carbono na economia, que se traduz em um preço de cerca de US\$38/t de $\mathrm{CO}_{2}$ Eq. Tal iniciativa, apesar de não ser capaz de alterar a trajetória mundial de emissões, deve servir de instrumento de negociação para a adesão de outros países ao esforço mundial de descarbonização das economias.

\section{Referências}

BABIKER, M.; JACOBY, H.D. Developing country effects of Kyototype emissions restrictions. MIT Joint Program on the Science and Policy of Global Change, n.53, out 1999.

BABIKER, M. H., RUTHERFORD, T. F. The economic effects of border measures in subglobal climate agreement. The Energy Journal, v. 26(4), p. 99-125, 2005.

BRASIL. Lei n.12.187, de 29 de dezembro de 2009. Institui a Política Nacional sobre Mudança do Clima-PNMC e dá outras providências. Diário Oficial da República Federativa do Brasil. Brasília, DF, 29 dez., 2009. Edição Extra. Seção 1, p.109. 2009a.

BRASIL. Ministério de Ciência e Tecnologia. Inventário Brasileiro das Emissões e Remoções Antrópicas de Gases de Efeito Estufa Informações Gerais e Valores Preliminares. 2009b. 
DIAZ, M. D. C., SCHWARTZMAN, S. Carbon offsets and land use in the Brazilian Amazon. In: Moutinho, P. e Schwartzman, S. (eds.) Tropical Deforestation and Climate Change, Environmental Defense Fund, Washington, DC, USA, 2005.

DIMARANAN, B.; MCDOUGALL, R. Global Trade, Assistance, and Production: The GTAP5 Data Base. Purdue University, West Lafayette, Indiana,Center for Global Trade Analysis, 2002.

DISSOU, Y., EYLAND, T. Carbon control policies, competitiveness, and border tax adjustments. Energy Economics,v. 33, p. 556-564, 2011.

FISCHER, C., FOX, A. K. Output-Based Allocation of Emissions Permits for Mitigating Tax and Trade Interactions. Land Economics, v. 83, p. 575-599, 2007.

FEIJÓ, F. T.; PORTO Jr., S. da S. Protocolo de Quioto e o BemEstar Econômico no Brasil: uma Análise Utilizando Equilíbrio Geral Computável. Análise Econômica (UFRGS), v. 51, p. 127-154, 2009.

G-8 HOKKAIDO SUMMIT, Ministry of foreign affairs of Japan, 2008. Disponível em: http://www.mofa.go.jp/policy/environment/warm/ coolearth50/initiative.pdf .Acesso em: 02, março, 2011.

GUILHOTO, J. J., LOPES, R., SEROA DA MOTTA, R. Impactos ambientais e regionais de cenários de crescimento da economia brasileira, 2002-12. Rio de Janeiro: IPEA, Texto para Discussão, 892, 2002.

GURGEL, A. C.; REILlY, J. M.; PALTSEV, S. Potential land use implications of a global biofuels industry. Journal of Agricultural \& Food Industrial Organization, v. 6, Article 9, 2008.

INTERGOVERNMENTAL PANEL ON CLIMATE CHANGE (IPCC). Climate change 2007: impacts, adaptation and vulnerability. Summary for policy makers, IPCC Secretariat, Geneva, Switzerland, 2007b. (http://www.ipcc.ch) Acessoem: 12, JULHO, 2011. 
KASAHARA, S., PALTSEV, S., REILLY, J., JACOBY, H., ELLERMAN, A. D. Climate change taxes and energy efficiency in Japan. Environmental and Resource Economics, v. 37, n. 2, p. 377-410, 2007.

\section{LIMA, E.M.C. Impactos de políticas climáticas internacionais sobre a} economia brasileira. 2011. Tese (Mestrado) - Faculdade de Economia, Administração e Ciências Contábeis -USP, Ribeirão Preto.

MELILLO, J. M., REILLY, J. M., KICKLIGHTER, D. W., GURGEL, A. C., CRONIN, T. W., PALTSEV, S., FELZER, B. S., WANG, X., SOKOLOV, A. P., SCHLOSSER, C. A. Indirect emissions from biofuels: how Important? Science, v. 326, p.1397-1399, 2009.

MOREIRA, H. M., GIOMETTI, A. B. O Protocolo de Quioto e as possibilidades de inserção do Brasil no mecanismo de desenvolvimento limpo por meio de projetos em energia limpa. Contexto Internacional, v. 30 (1), p. 9-47, 2008.

OLIVIER, J. G. J., BERDOWSKI, J. J. M. Global emission sources and sinks. In: Berdowski, J., Guicherit, R., Heij, B. J. (Ed.). The climate system. Lisse: Swets and Zeitlinger Publishers, 2001. p. 33-78.

PALTSEV, S.; REILLY, J.; JACOBY, H.; ECKAUS, R.; MCFARLAND, J.; SAROFIM, M.; ASADOORIAN, M.; BABIKER, M. The MIT Emissions Prediction and Policy Analysis (EPPA) Model: Version 4. MITJoint Program on the Science and Policy of Global Change, $n$. 125, ago 2005.

PALTSEV, S., REILlY, J.M, JACOBY, H.D, GURGEL, A.C., METCALF, G.E., SOKOLOV, A.P., HOLAK, J.F.Assessment of U.S. GHG cap-and-trade proposals.Climate Policy, v. 8, p. 395-420, 2008.

PALTSEV, S.; REILLY, J. M.; JACOBY, H. D.; MORRIS, J. F.The cost of climate policy in the United States. MIT Joint Program on the Science and Policy of Global Change, Cambridge, n. 173, Apr. 2009. 
REILLY, J., PALTSEV, S. European Greenhouse Gas Emissions Trading: A System in Transition. In: Miguel, C. de, Labandeira, X., Manzano, B. (edits.) Economic Modelling of Climate Change and Energy Policies, Edward Elgar Publishing: Cheltenham, UK; \& Northampton, MA, USA, p. 45-64, 2006.

REINAUD, J. Industrial competitiveness under the European Union Emissions trading scheme. International Energy Agency Information Paper, Dec. 2004. Disponível em: <http://194.245.121.74/fileadmin/ gruppen/bdz/Themen/Umwelt/IEA-Studie_11-2004.pdf $>$. Acesso em: 14 julho. 2011.

SADOULET, E., DE JANVRY, A. Quantitative development policy analysis. Baltimore: The Johns Hopkins University,397 p., 1995.

SHOVEN, J. B.; WHALLEY, J. Applying general equilibrium. 3.Ed. Cambridge: Cambridge University Press, 1998. 299 p.

SILVA, J.G.da. GURGEL, A. C. Impactos econômicos de cenários de políticas climáticas para o Brasil. Pesquisa e Planejamento Econômico,v. 42, n. 1, p. 93 - 135, 2012.

TOURINHO, O.A.F.; DA MOTTA, R.S.; ALVES, Y.L.B. Uma aplicação ambiental de um modelo de equílibrio geral. IPEA. Texto para discussão, n. 976, Rio de Janeiro, 2003.

VIOLA, E. O Brasil na arena internacional da mitigação da política climática. Disponível em: http://www.cindesbrasil.org/index2. php?option $=$ com_docman\&task $=$ doc_view\&Itemid $=47,2009$. Acesso em 23 de Julho de 2010.

US CONGRESS.The American Clean Energy and Security Act of 2009 (H.R. 2454). US House of Representative, Washington, D.C., 2009. Disponívelem<http://frwebgate.access.gpo.gov/cgi-bin/getdoc. 
cgi?dbname=111_cong_bills\&docid=f:h2454pcs.txt.pdf $>$.Acessoem 25 abr. 2011.

WASHINGTON, W. M.; KNUTTI R.; MEEHL G. A.; TENG, H.; TEBALDI H, C; LAWRENCE, D; BUJA, L; STRAND, W.G.: How much climate change can be avoided by mitigation?, Geophysical. Research Letters. , 36 , L08703, doi:10.1029/2008GL037074, 2009.

YU, CHANG MAN. Sequestro florestal do carbono no Brasil: Dimensões políticas, socioeconômicas e ecológicas./ Chang Man Yu - São Paulo: Annablume, IEB, 2004

\section{APÊNDICE - TARIFAS COMPENSATÓRIAS DE CARBONO}

Tabela A1 - Tarifas compensatórias de carbono aplicadas pelos EUA em 2015

\begin{tabular}{lccccccc}
\hline & Culturas & Pecuária & Silvicultura & Alimentos & EINT & Outros & Transportes \\
\hline CAN & $16 \%$ & $9 \%$ & $12 \%$ & $5 \%$ & $34 \%$ & $5 \%$ & $133 \%$ \\
MEX & $10 \%$ & $14 \%$ & $8 \%$ & $6 \%$ & $24 \%$ & $1 \%$ & $196 \%$ \\
JPN & $16 \%$ & $30 \%$ & $13 \%$ & $8 \%$ & $22 \%$ & $2 \%$ & $33 \%$ \\
ANZ & $14 \%$ & $12 \%$ & $15 \%$ & $14 \%$ & $22 \%$ & $4 \%$ & $67 \%$ \\
EUR & $20 \%$ & $11 \%$ & $9 \%$ & $9 \%$ & $19 \%$ & $3 \%$ & $51 \%$ \\
ROE & $50 \%$ & $13 \%$ & $17 \%$ & $18 \%$ & $91 \%$ & $18 \%$ & $69 \%$ \\
RUS & $24 \%$ & $16 \%$ & $57 \%$ & $9 \%$ & $88 \%$ & $9 \%$ & $182 \%$ \\
ASI & $13 \%$ & $34 \%$ & $68 \%$ & $10 \%$ & $53 \%$ & $5 \%$ & $117 \%$ \\
CHN & $29 \%$ & $20 \%$ & $17 \%$ & $24 \%$ & $79 \%$ & $9 \%$ & $60 \%$ \\
IND & $4 \%$ & $1 \%$ & $0 \%$ & $20 \%$ & $85 \%$ & $7 \%$ & $57 \%$ \\
BRA & $40 \%$ & $17 \%$ & $19 \%$ & $13 \%$ & $47 \%$ & $4 \%$ & $214 \%$ \\
AFR & $8 \%$ & $7 \%$ & $9 \%$ & $8 \%$ & $54 \%$ & $8 \%$ & $126 \%$ \\
MES & $18 \%$ & $12 \%$ & $4 \%$ & $26 \%$ & $191 \%$ & $14 \%$ & $215 \%$ \\
LAM & $17 \%$ & $7 \%$ & $14 \%$ & $12 \%$ & $52 \%$ & $10 \%$ & $121 \%$ \\
REA & $5 \%$ & $7 \%$ & $4 \%$ & $11 \%$ & $187 \%$ & $20 \%$ & $88 \%$ \\
\hline
\end{tabular}

Fonte: resultados da pesquisa 
Tabela A2 - Tarifas compensatórias de carbono aplicadas pelos EUA em 2030

\begin{tabular}{lccccccc}
\hline & Culturas & Pecuária & Silvicultura & Alimentos & EINT & Outros & Transportes \\
\hline CAN & $105 \%$ & $62 \%$ & $81 \%$ & $14 \%$ & $222 \%$ & $31 \%$ & $867 \%$ \\
MEX & $61 \%$ & $91 \%$ & $65 \%$ & $20 \%$ & $170 \%$ & $10 \%$ & $1440 \%$ \\
JPN & $97 \%$ & $209 \%$ & $94 \%$ & $22 \%$ & $135 \%$ & $7 \%$ & $214 \%$ \\
ANZ & $85 \%$ & $84 \%$ & $105 \%$ & $31 \%$ & $138 \%$ & $18 \%$ & $436 \%$ \\
EUR & $100 \%$ & $79 \%$ & $67 \%$ & $31 \%$ & $118 \%$ & $11 \%$ & $345 \%$ \\
ROE & $166 \%$ & $82 \%$ & $111 \%$ & $83 \%$ & $642 \%$ & $87 \%$ & $469 \%$ \\
RUS & $102 \%$ & $106 \%$ & $387 \%$ & $52 \%$ & $617 \%$ & $37 \%$ & $1263 \%$ \\
ASI & $72 \%$ & $236 \%$ & $795 \%$ & $52 \%$ & $341 \%$ & $21 \%$ & $791 \%$ \\
CHN & $185 \%$ & $142 \%$ & $105 \%$ & $114 \%$ & $437 \%$ & $35 \%$ & $364 \%$ \\
IND & $4 \%$ & $2 \%$ & $0 \%$ & $95 \%$ & $534 \%$ & $20 \%$ & $316 \%$ \\
BRA & $166 \%$ & $117 \%$ & $156 \%$ & $34 \%$ & $316 \%$ & $18 \%$ & $1423 \%$ \\
AFR & $31 \%$ & $47 \%$ & $47 \%$ & $33 \%$ & $374 \%$ & $48 \%$ & $824 \%$ \\
MES & $114 \%$ & $82 \%$ & $28 \%$ & $132 \%$ & $1346 \%$ & $87 \%$ & $1492 \%$ \\
LAM & $108 \%$ & $52 \%$ & $99 \%$ & $41 \%$ & $360 \%$ & $33 \%$ & $794 \%$ \\
REA & $26 \%$ & $49 \%$ & $26 \%$ & $66 \%$ & $1229 \%$ & $72 \%$ & $541 \%$ \\
\hline
\end{tabular}

Fonte: resultados da pesquisa 